Review

\title{
Amanita phalloides poisoning: Mechanisms of toxicity and treatment
}

\author{
Juliana Garcia ${ }^{\mathrm{a}, *}$, Vera M. Costa ${ }^{\mathrm{a}}$, Alexandra Carvalho ${ }^{\mathrm{b}}$, Paula Baptistac, Paula Guedes de \\ Pinho $^{\mathrm{a}}$, Maria de Lourdes Bastos ${ }^{\mathrm{a}}$, Félix Carvalho ${ }^{\mathrm{a}, * *}$ \\ a UCIBIO-REQUIMTE, Laboratory of Toxicology, Department of Biological Sciences, Faculty of Pharmacy, University of Porto, Rua José Viterbo Ferreira $n^{\circ} 228$, \\ 4050-313 Porto, Portugal \\ ${ }^{\mathrm{b}}$ Department of Cell and Molecular Biology, Computational and Systems Biology, Uppsala University, Biomedical Center, Box 596,75124 Uppsala, Sweden \\ ' CIMO/School of Agriculture, Polytechnique Institute of Bragança, Campus de Santa Apolónia, Apartado 1172, 5301-854 Bragança, Portugal
}

\section{A R T I C L E I N F O}

\section{Article history:}

Received 10 April 2015

Received in revised form 8 September 2015

Accepted 10 September 2015

Available online 12 September 2015

\section{Keywords:}

Amanita phalloides

Amatoxins

RNA polymerase II

Liver

Kidney

Therapy

\begin{abstract}
A B S T R A C T
Amanita phalloides, also known as 'death cap', is one of the most poisonous mushrooms, being involved in the majority of human fatal cases of mushroom poisoning worldwide. This species contains three main groups of toxins: amatoxins, phallotoxins, and virotoxins. From these, amatoxins, especially $\alpha$-amanitin, are the main responsible for the toxic effects in humans. It is recognized that $\alpha$-amanitin inhibits RNA polymerase II, causing protein deficit and ultimately cell death, although other mechanisms are thought to be involved. The liver is the main target organ of toxicity, but other organs are also affected, especially the kidneys. Intoxication symptoms usually appear after a latent period and may include gastrointestinal disorders followed by jaundice, seizures, and coma, culminating in death. Therapy consists in supportive measures, gastric decontamination, drug therapy and, ultimately, liver transplantation if clinical condition worsens. The discovery of an effective antidote is still a major unsolved issue. The present paper examines the clinical toxicology of $A$. phalloides, providing the currently available information on the mechanisms of toxicityinvolved and on the current knowledge on the treatment prescribed against this type of mushrooms. Antidotal perspectives will be raised as to set the pace to new and improved therapy against these mushrooms.
\end{abstract}

(c) 2015 Elsevier Ltd. All rights reserved.

\section{Contents}

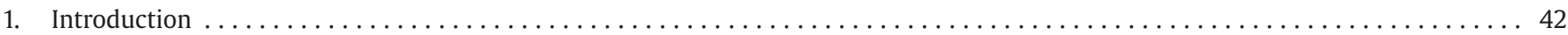

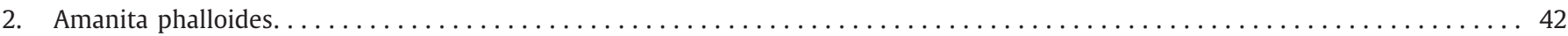

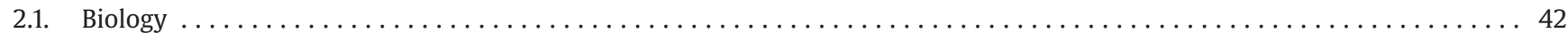

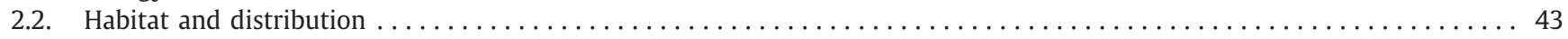

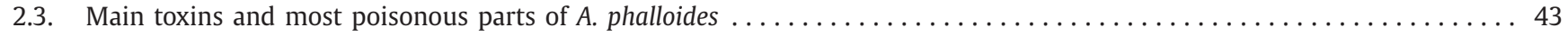

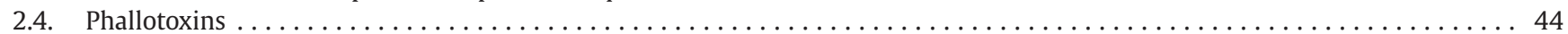

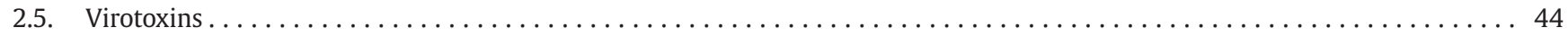

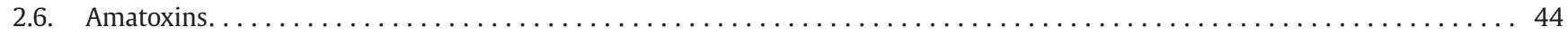

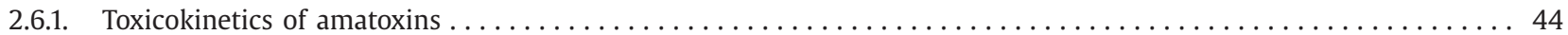

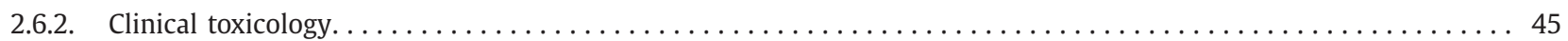

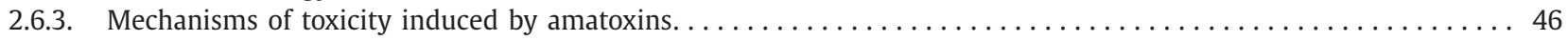

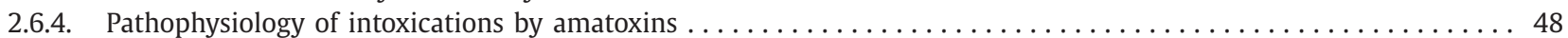

Abbreviations: ALT, alanine aminotransferase; AST, aspartate aminotransferase; CIAV, antipoison information center (Centro de Informação Antivenenos); GI, gastrointesti-

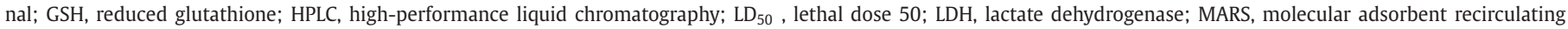

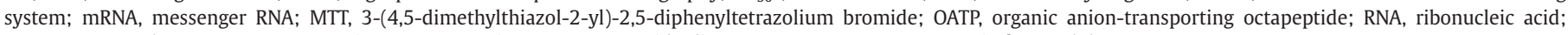
RNAP II, RNA polymerase II; ROS, reactive oxygen species; SOD, superoxide dismutase; TNF- $\alpha$, tumor necrosis factor alpha.

* Corresponding author.

** Corresponding author.

E-mail addresses: jugarcia_18@hotmail.com (J. Garcia), felixdc@ff.up.pt (F. Carvalho). 


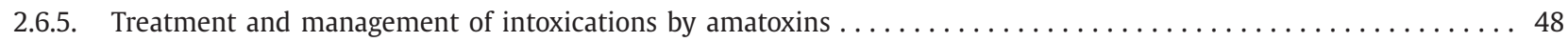

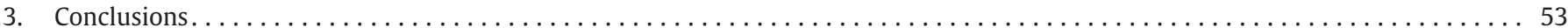

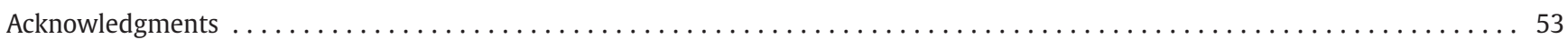

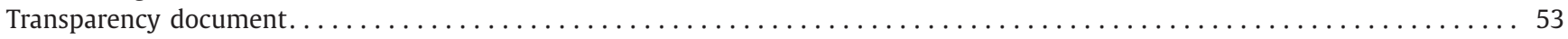

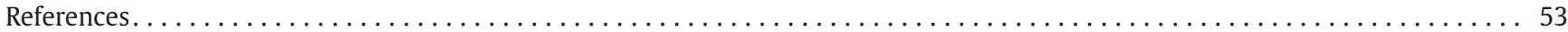

\section{Introduction}

In the past few decades, mushrooms have become popular in the human diet as a result of their exquisite taste and texture, protein content, and an expanding body of scientific research supporting their health benefits (Cheung, 2010). The increased public demand for wild edible mushrooms contributes to an increased interest in their picking and consumption (Pilz and Molina, 2002), which enhances the risk of intoxications by toxic mushrooms (Eren et al., 2010). Despite warnings on the risks, collectors may confuse edible with toxic mushrooms, due to misidentification based on morphological characteristics. Toxic mushrooms can be grouped based on their toxic components: cyclopeptides, gyromitrin, muscarine coprine, isoxazoles, orellanine, psilocybin, and gastrointestinal irritants (Karlson-Stiber and Persson, 2003). From these, cyclopeptides-containing mushrooms are the most toxic species throughout the world, being responsible for 90-95\% of human fatalities (Karlson-Stiber and Persson, 2003). The main toxic agents are amatoxins that are present in three genera: Amanita (mainly Amanita phalloides, A. virosa and A. verna); Lepiota (the most frequently reported is L. brunneoincarnata) and Galerina (the most common being Galerina marginata) (Table 1) (Enjalbert et al., 2002). Among these species, A. phalloides is responsible for the majority of fatal cases due to mushroom poisoning (Alves et al., 2001; Bonnet and Basson, 2002; Diaz, 2005b; Vetter, 1998). Amatoxin poisoning usually has a bad prognosis due to the high risk of liver failure. There are no worldwide widely accepted guidelines regarding the treatment of amatoxins-intoxicated patients and therapy comprises supportive care and numerous combinations of drugs, including antibiotics and antioxidant ther-

Table 1

Amatoxin-containing mushroom species from the genera Amanita, Galerina and Lepiota.

\begin{tabular}{lll}
\hline Amanita sp. & Galerina sp. & Lepiota sp. \\
\hline A. phalloides & G. badipes & L. brunneoincarnata \\
A. bisporigera & G. beinrothii & L. brunneolilacea \\
A. decipiens & G. fasciculate & L. castanea \\
A. hygroscopica & G. helvoliceps & L. clypeolaria \\
A. ocreata & G. marginata & L. clypeolarioides \\
A. suballiacea & G. sulciceps & L. felina \\
A. tenuifolia & G. unicolor & L. fulvella \\
A. verna & G. venenata & L. fuscovinacea \\
A. virosa & & L. griseovirens \\
& & L. heimii \\
& L. helveoloides \\
& L. kuehneri \\
& L. langei \\
& L. lilacea \\
& L. locanensis \\
& L. ochraceofulva \\
& L. pseudohelveola \\
& L. pseudolilacea \\
& L. rufescens \\
& L. subincarnata \\
& L. xanthophylla \\
\hline
\end{tabular}

Source: Enjalbert et al. (2002). apy. Several antidotes have been used, namely benzylpenicillin, ceftazidime, silybin, and N-acetylcysteine. However, none of them has been clearly proven to have great clinical efficacy and, therefore, a high mortality rate $(10-30 \%)$ is still verified (Enjalbert et al., 2002; Escudie et al., 2007; Ganzert et al., 2005). Survival depends on the degree of hepatic destruction, the ability of the remaining liver cells to regenerate, and the management of complications that may develop during the intoxication course (Koda-Kimble et al., 2012). Liver transplantation has significantly improved the survival rate in $A$. phalloides poisoned patients and remains the cornerstone of treatment in selected patients with fulminant hepatic failure (Broussard et al., 2001; Pinson et al., 1990). However, organ transplant services totally depend on available organ donation, which is not always possible, being also a costly and risky procedure.

Accurate estimates of worldwide poison by amatoxinscontaining mushrooms are difficult to establish due to the lack of case reporting in hospital emergency rooms. To the best of our knowledge, in Portugal there is only one retrospective analysis that gathered the data of 93 cases of mushroom poisonings admitted in ten Portuguese hospitals between 1990 and 2008. Of those, $63.4 \%$ were attributed to amatoxins-containing mushrooms, $11.8 \%$ having a fatal outcome (Brandão et al., 2011). In USA, a total of 6600 mushroom intoxications were reported to the national poison data system of the American association of poison control centers in 2012 (Mowry et al., 2013). Among these cases, $82.7 \%$ were attributed to unknown mushroom types while cyclopeptides-containing mushrooms represented 44 cases (4 patients died) (Mowry et al., 2013). A retrospective case study concerning the prevalence and the circumstances of exposure to mushrooms reported to the Swiss toxicological information center between January 1995 and December 2009 described a total of 32 confirmed cases of amatoxin poisoning, 5 with a fatal outcome (Schenk-Jaeger et al., 2012). A retrospective study of all amatoxin poisoning cases recorded over 15 years (1988-2002) in the Toxicological Unit of Careggi General Hospital (Florence University) reported 111 intoxications by amatoxins-containing mushrooms treated with benzylpenicillin (2 patients died) (Giannini et al., 2007), while available clinical French data described 45 patients (1984-1989) treated with benzylpenicillin plus silybin (8 patients died) (Jaeger et al., 1993). From the above information, it is clear that amatoxin poisoning has emerged as a serious public health problem worldwide. Therefore, this review aims to provide the state of the art concerning the mechanisms of toxicity, patterns of clinical presentation and management of amatoxin poisoning, focusing on the efficacy and limitations of the most commonly used antidotes.

\section{Amanita phalloides}

\subsection{Biology}

Amatoxins are present in several Basidiomycota species belonging to three genera, i.e. Amanita, Galerina, and Lepiota (Barceloux, 2008; Block et al., 1955; Kaneko et al., 2001). Table 1 lists the main amatoxin-containing species (Enjalbert et al., 2002). As case 
reports of fatalities following consumption of amatoxins-containing mushrooms are mainly associated with $A$. phalloides (Barceloux, 2008), this species will be the main focus of the present review.

The smooth moist cap of $A$. phalloides is greenish yellow, darker in the center and faintly streaked radially. The cap is $6-12.5 \mathrm{~cm}$ across and easily peeled. The stalk is smooth, white and $6-12.5 \mathrm{~cm}$ high. There is an irregular ring near the top of the stalk and a bulbous cup at the base. The fruiting body emanates a sweetish and not unpleasant smell. Its taste is pleasant, according to the survivors after intoxication (Bonnet and Basson, 2002). A. phalloides is distinguished from other species, like Volvariella volvacea, by their irregular ring near the top of the stalk, the bulbous cup at the base and white gills under the cap that are not attached to the stem. The morphology of the bulbous cup has been an important feature to distinguish Amanita from other resembling genera. However, inexperienced collectors break the specimen off at the stem destroying or neglecting some of these characteristics, which puts the consumers at risk of intoxication (Olson et al., 1982). Moreover, non-Amanita containing-amatoxins species exist placing more people at risk (Olson et al., 1982). Additionally, mushroom species have mutable appearances at different times of year and at different locations, depending on weather, soil, and time of harvest, which makes more challenging the correct mushroom identification for collectors.

\subsection{Habitat and distribution}

A. phalloides is the predominant European poisonous mushroom, particularly in Central and Occidental Europe (Barceloux, 2008). Several cases of $A$. phalloides poisoning have also been reported in northeastern United States (Pond et al., 1986), Central and South America, Asia (Karlson-Stiber and Persson, 2003), Australia, (Trim et al., 1999) and Africa (Reid and Eicker, 1991). This species is an ectomycorrhizal fungus that forms symbiotic relationships with a variety of tree species, such as beech, oak, chestnut, and pine. The best seasons of the year for A. phalloides fructification are spring, late summer, and autumn (Bonnet and Basson, 2002), and therefore the majority of the intoxication cases occur in those seasons.

\subsection{Main toxins and most poisonous parts of A. phalloides}

A. phalloides contains three classes of cyclic peptide toxins, which can be grouped into amatoxins, phallotoxins, and virotoxins. All groups of toxins contain a tryptophan residue substituted at position 2 of the indol ring by a sulfur atom (Vetter, 1998) (Figs. 1-3). They have distinct toxicological profiles: amatoxins are highly toxic [intraperitoneal lethal dose $50\left(\mathrm{LD}_{50}\right) 0.4-0.8 \mathrm{mg} / \mathrm{kg}$, in the white mouse] causing death within 2-8 days, whereas phallotoxins and virotoxins are less toxic (intraperitoneal $\mathrm{LD}_{50} 1-20 \mathrm{mg} / \mathrm{kg}$, in the white mouse) but act quickly, causing death within 2-5 h (Vetter, 1998).

Several studies have studied the content and distribution of the main toxins in different carpophore tissues and in several development stages of A. phalloides (Enjalbert et al., 1996, 1999, 1993; Garcia et al., 2015c). An unequal distribution of the toxins throughout the carpophore exists. The highest amatoxins content was found in the ring, gills and cap, while the volva had the richest in the amount of phallotoxins (Enjalbert et al., 1993; Garcia et al., 2015c). The collection site and the age of the collected species affect the quantity of toxins on the carpophore elements (Enjalbert et al., 1996, 1993; Garcia et al., 2015c). The collection site (mainly soil characteristics) determines toxins' composition of each mushroom, mostly the predominance of either acidic or neutral phallotoxins (Enjalbert et al., 1996; Garcia et al., 2015c). Regarding the maturation state, the content of amatoxins is relatively high during the

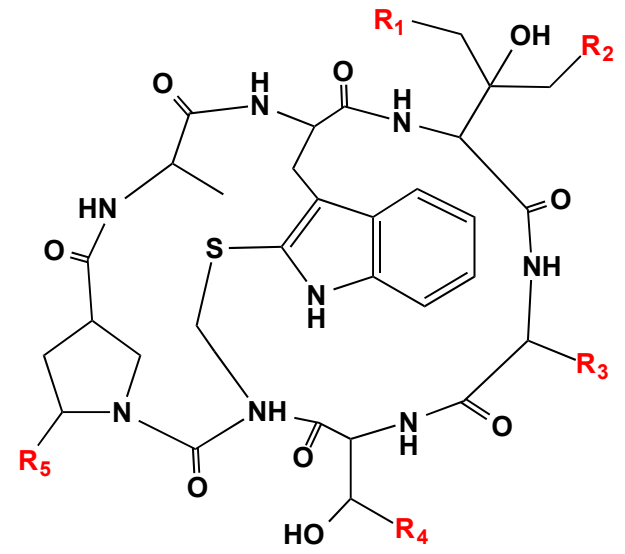

\begin{tabular}{llllll}
\hline & R1 & R2 & $\mathbf{R 3}$ & $\mathbf{R} 4$ & R5 \\
\hline Phalloidin & $\mathrm{OH}$ & $\mathrm{H}$ & $\mathrm{CH}_{3}$ & $\mathrm{CH}_{3}$ & $\mathrm{OH}$ \\
Phalloin & $\mathrm{H}$ & $\mathrm{H}$ & $\mathrm{CH}_{3}$ & $\mathrm{CH}_{3}$ & $\mathrm{OH}$ \\
Prophallin & $\mathrm{H}$ & $\mathrm{H}$ & $\mathrm{CH}_{3}$ & $\mathrm{CH}_{3}$ & $\mathrm{H}$ \\
Phallisin & $\mathrm{OH}$ & $\mathrm{OH}$ & $\mathrm{CH}_{3}$ & $\mathrm{CH}_{3}$ & $\mathrm{OH}$ \\
Phallacin & $\mathrm{H}$ & $\mathrm{H}$ & $\mathrm{CH}\left(\mathrm{CH}_{3}\right)_{2}$ & $\mathrm{COOH}$ & $\mathrm{OH}$ \\
Phallacidin & $\mathrm{OH}$ & $\mathrm{H}$ & $\mathrm{CH}\left(\mathrm{CH}_{3}\right)_{2}$ & $\mathrm{COOH}$ & $\mathrm{OH}$ \\
Phallisacin & $\mathrm{OH}$ & $\mathrm{OH}$ & $\mathrm{CH}\left(\mathrm{CH}_{3}\right)_{2}$ & $\mathrm{COOH}$ & $\mathrm{OH}$ \\
\hline
\end{tabular}

Fig. 1. Chemical structure of phallotoxins.<smiles>[X]c1[nH]c2ccccc2c1CC(NC(=O)C(C)NC(=O)C1CN(C(=O)C(C)NC(=O)C(C)O)C(O)C1O)C(=O)NC(C)C([R2])NC(=O)C(C)O</smiles>

\begin{tabular}{llll}
\hline & $\mathbf{X}$ & $\mathbf{R 1}$ & $\mathbf{R 2}$ \\
\hline Viroidin & $\mathrm{SO}_{2}$ & $\mathrm{CH}_{3}$ & $\mathrm{CH}\left(\mathrm{CH}_{3}\right)_{2}$ \\
Deoxoviroidin & $\mathrm{SO}$ & $\mathrm{CH}_{3}$ & $\mathrm{CH}\left(\mathrm{CH}_{3}\right)_{2}$ \\
Alaviroidin & $\mathrm{SO}_{2}$ & $\mathrm{CH}_{3}$ & $\mathrm{CH}_{3}$ \\
Viroisin & $\mathrm{SO}_{2}$ & $\mathrm{CH}_{2} \mathrm{OH}$ & $\mathrm{CH}\left(\mathrm{CH}_{3}\right)_{2}$ \\
Deoxoviroisin & $\mathrm{SO}$ & $\mathrm{CH}_{2} \mathrm{OH}$ & $\mathrm{CH}\left(\mathrm{CH}_{3}\right)_{2}$ \\
\hline
\end{tabular}

Fig. 2. Chemical structure of virotoxins.

early development stages (button, button with broken outer veil, and pileus revealed from outer veil) and decreases in the mature (completely developed fruit body with convex cap) and old (wilted fruit body with reflexed cap) stages (Garcia et al., 2015c; Hu et al., 2012). 


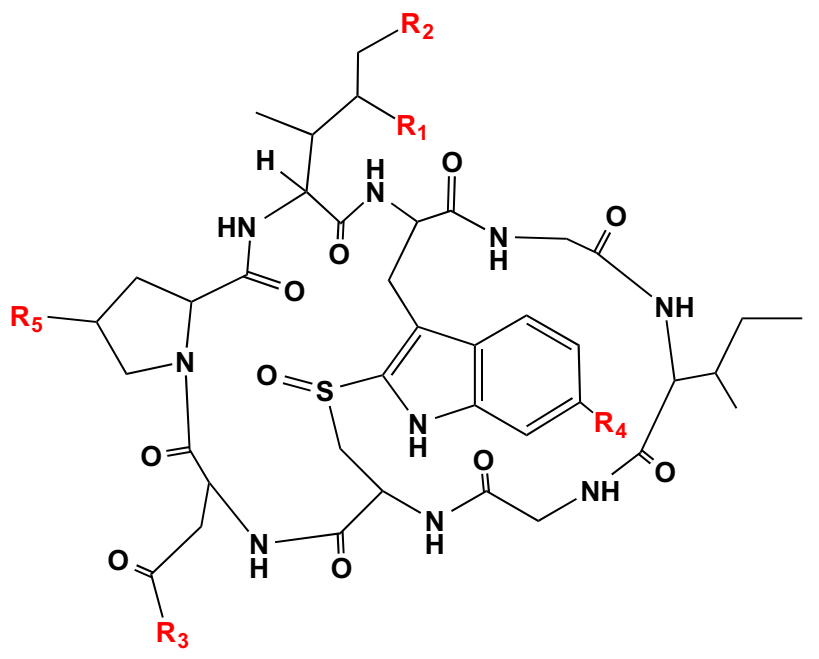

\begin{tabular}{llllll}
\hline & $\mathbf{R} 1$ & $\mathbf{R 2}$ & $\mathbf{R 3}$ & $\mathbf{R} 4$ & $\mathbf{R}$ \\
\hline a-amanitin & $\mathrm{CH}_{2} \mathrm{OH}$ & $\mathrm{OH}$ & $\mathrm{NH}_{2}$ & $\mathrm{OH}$ & $\mathrm{OH}$ \\
p-amanitin & $\mathrm{CH}_{2} \mathrm{OH}$ & $\mathrm{OH}$ & $\mathrm{OH}$ & $\mathrm{OH}$ & $\mathrm{OH}$ \\
-amanitin & $\mathrm{CH}_{3}$ & $\mathrm{OH}$ & $\mathrm{NH}_{2}$ & $\mathrm{OH}$ & $\mathrm{OH}$ \\
z-amanitin & $\mathrm{CH}_{3}$ & $\mathrm{OH}$ & $\mathrm{OH}$ & $\mathrm{OH}$ & $\mathrm{OH}$ \\
Amanin & $\mathrm{CH}_{2} \mathrm{OH}$ & $\mathrm{OH}$ & $\mathrm{OH}$ & $\mathrm{H}$ & $\mathrm{OH}$ \\
Amanin amide & $\mathrm{CH}_{2} \mathrm{OH}$ & $\mathrm{OH}$ & $\mathrm{NH}_{2}$ & $\mathrm{H}$ & $\mathrm{OH}$ \\
Amanullin & $\mathrm{CH}_{3}$ & $\mathrm{H}$ & $\mathrm{NH}_{2}$ & $\mathrm{OH}$ & $\mathrm{OH}$ \\
Amanullic acid & $\mathrm{CH}_{3}$ & $\mathrm{H}$ & $\mathrm{OH}^{2}$ & $\mathrm{OH}$ & $\mathrm{OH}$ \\
Proamanullin & $\mathrm{CH}_{3}$ & $\mathrm{H}$ & $\mathrm{NH}_{2}$ & $\mathrm{OH}$ & $\mathrm{H}$ \\
\hline & & & & &
\end{tabular}

Fig. 3. Chemical structure of amatoxins.

\subsection{Phallotoxins}

Phallotoxins are bicyclic heptapeptides, first isolated from A. phalloides (Lynen and Wieland, 1938) and formed by at least seven different compounds: phalloidin, phalloin, prophallin, phallisin, phallacin, phallacidin, and phallisacin (Fig. 1) (Vetter, 1998). From these, phalloidin, phalloin, prophallin, and phallisin are classified as neutral phallotoxins, whereas phallacin, phallacidin, and phallisacin are acidic phallotoxins.

The in vitro actions of phallotoxins have been thoroughly characterized (Cooper, 1987; Dancker et al., 1975; Gabbiani et al., 1975; Wieland, 1976). Phallotoxins bind to F-actin, which stabilizes the actin filaments and prevents microfilaments depolymerization, disturbing the correct function of the cytoskeleton (Wieland, 1976). They are only toxic to mammals if parenterically administered since phallotoxins are not absorbed through the gastrointestinal tract (Wieland and Faulstich, 1978). The major in vivo toxic effect produced by intraperitoneal administration of phallotoxin affects the liver (Wieland, 1976). The $\mathrm{LD}_{50}$ values of phallotoxins for white mouse are listed in Table 2. All phallotoxins have similar intraperitoneal $\mathrm{LD}_{50}$ (ranging from 1.5 to $4.5 \mathrm{mg} / \mathrm{kg}$ ), except prophalloin, which seems to be less toxic ( $>20 \mathrm{mg} / \mathrm{kg}$ ). No significant toxicological data on neutral and acid phallotoxins exist so far, thus no final conclusions can be drawn regarding their putative toxicological differences.

\subsection{Virotoxins}

Virotoxins are monocyclic peptides formed by at least five different compounds: alaviroidin, viroisin, deoxoviroisin, viroidin, and deoxoviroidin (Fig. 2) (Vetter, 1998). The structure and biological activity of virotoxins are similar to that of phallotoxins, thus suggesting that virotoxins are biosynthetically derived from phallotoxins or share common precursor pathways (Brossi, 1991; Derelanko and Hollinger, 2001). As with phallotoxins, virotoxins are not considered to have significant toxic effects after oral exposure. At the molecular level, like phallotoxins, they interact with actin, stabilizing the bonds between actin monomers and preventing microfilaments depolymerization. However, the ultraviolet-spectra of interaction between actin and virotoxins is different from that of actinphallotoxins, suggesting a different molecular interaction (Turcotte et al., 1984). Virotoxins have a more flexible structure when compared with phallotoxins and the presence of two additional hydroxyl groups may provide different reactivity (Fig. 2) (Faulstich et al., 1980; Wong, 2013). The intraperitoneal $L_{50}$ of virotoxins in mice ranges from 1.0 to $5.1 \mathrm{mg} / \mathrm{kg}$ (Table 2) and their main toxicological feature is hemorrhagic hepatic necrosis caused by an interaction of the virotoxins with outer surface of the hepatocyte through unknown mechanisms (Loranger et al., 1985). At this point, the role of virotoxins in human toxicity remains unclear, although due to its poor oral absorption, little clinical importance is given to this class of toxins.

\subsection{Amatoxins}

Amatoxins have been identified as bicyclic octapeptides with molecular weight of around $900 \mathrm{~g} / \mathrm{mol}$, formed by at least nine different compounds: $\alpha$-amanitin, $\beta$-amanitin, $\gamma$-amanitin, $\varepsilon$ amanitin, amanin, amaninamide, amanullin, amanullinic acid, and proamanullin (Fig. 3) (Vetter, 1998). From these, $\alpha$-amanitin, $\gamma$ amanitin, amaninamide, amanullin, and proamanullin are classified as neutral amatoxins, whereas $\beta$-amanitin, $\varepsilon$-amanitin, amanin, and amanullic acid are acidic amatoxins. The intraperitoneal $L_{50}$ of amatoxins in mice ranges from 0.3 to $20 \mathrm{mg} / \mathrm{kg}$ (Table 2). The main toxicological studies were focused on $\alpha$-amanitin and $\beta$ amanitin toxins, thus no final conclusions can be drawn regarding the potential differences between neutral and acid amatoxins. Amatoxins only differ by the number of hydroxyl groups and by an amide carboxyl exchange (Fig. 3) (Vetter, 1998). These toxins have great heat stability and this property combined with their solubility in water make them exceptionally toxic as they are not destroyed by cooking or drying (Wieland and Faulstich, 1978). In addition, amatoxins are resistant to enzyme and acid degradation, and therefore when ingested they will not be inactivated in the gastrointestinal tract (Wieland and Faulstich, 1978). A fatal case was reported after consuming $A$. phalloides frozen during 7-8 months, thus demonstrating that these compounds also resist to freeze/thawing processes (Himmelmann et al., 2001). Additionally, amatoxins decompose very slowly when stored in open, aqueous solutions or following prolonged exposure to sun or neon light (Barceloux, 2008).

\subsubsection{Toxicokinetics of amatoxins}

The toxicokinetics of $\alpha$-amanitin has been studied in animals and through data obtained in reports of human poisoning by amatoxins (Faulstich et al., 1985; Jaeger et al., 1993). Amatoxins are readily absorbed from the human gastrointestinal tract and can be detected radioimmunologically in the urine as early as $90-120 \mathrm{~min}$ after ingestion (Homann et al., 1986). Amatoxins do not bind to albumin (Faulstich et al., 1985) being rapidly eliminated from the blood and distributed to liver and kidneys within $48 \mathrm{~h}$ (Jaeger et al., 1993). After intravenous administration in dogs, the plasma half-life of amatoxins was shown to be short, ranging from 26.7 to $49.6 \mathrm{~min}$ and they were not detectable in plasma after $4-6 \mathrm{~h}$. The total body clearance was between 2.7 and $6.2 \mathrm{ml} / \mathrm{min} / \mathrm{kg}$ (Faulstich et al., 1985). 
Table 2

$\mathrm{LD}_{50}$ values for amatoxins, phallotoxins, and virotoxins in different species and administration routes.

\begin{tabular}{|c|c|c|c|c|c|c|}
\hline Toxin & Mice $^{\mathrm{a}}$ & Rat $^{\mathrm{a}}$ & $\operatorname{Dog}^{\mathrm{a}}$ & Human $^{\mathrm{a}}$ & Administration route & References \\
\hline \multicolumn{7}{|l|}{ Amatoxins } \\
\hline \multirow[t]{4}{*}{$\alpha$-amanitin } & $0.3-0.6$ & 4.0 & & & Intraperitoneal & (Wieland and Faulstich, 1978) \\
\hline & 0.002 & 0.01 & & & Intracerebroventricular & (Wieland and Faulstich, 1978) \\
\hline & & & 0.1 & & Intravenous & (Wieland and Faulstich, 1978) \\
\hline & & & & 0.1 & Oral & (Vetter, 1998) \\
\hline$\beta$-amanitin & 0.5 & & & & Intraperitoneal & (Deshpande, 2002) \\
\hline$\gamma$-amanitin & $0.2-0.5$ & & & & Intraperitoneal & (Deshpande, 2002) \\
\hline$\varepsilon$-amanitin & $0.3-0.6$ & & & & Intraperitoneal & (Deshpande, 2002) \\
\hline Amanin & 0.5 & & & & Intraperitoneal & (Deshpande, 2002) \\
\hline Amanin amide & 0.5 & & & & Intraperitoneal & (Deshpande, 2002) \\
\hline Amanullin & $>20$ & & & & Intraperitoneal & (Deshpande, 2002) \\
\hline Amanullinic acid & $>20$ & & & & Intraperitoneal & (Deshpande, 2002) \\
\hline Proamanullin & $>20$ & & & & Intraperitoneal & (Deshpande, 2002) \\
\hline \multicolumn{7}{|l|}{ Phallotoxins } \\
\hline Phalloin & 1.5 & & & & Intraperitoneal & (Deshpande, 2002) \\
\hline Phalloidin & 2 & & & & Intraperitoneal & (Deshpande, 2002) \\
\hline Phallisin & 2 & & & & Intraperitoneal & (Deshpande, 2002) \\
\hline Prophalloin & $>20$ & & & & Intraperitoneal & (Deshpande, 2002) \\
\hline Phallacin & 1.5 & & & & Intraperitoneal & (Deshpande, 2002) \\
\hline Phallacidin & 1.5 & & & & Intraperitoneal & (Deshpande, 2002) \\
\hline Phallisacin & 4.5 & & & & Intraperitoneal & (Deshpande, 2002) \\
\hline \multicolumn{7}{|l|}{ Virotoxins } \\
\hline Alaviroidin & 3.7 & & & & Intraperitoneal & (Loranger et al., 1985) \\
\hline Viroisin & 1.68 & & & & Intraperitoneal & (Loranger et al., 1985) \\
\hline Deoxoviroisin & 3.35 & & & & Intraperitoneal & (Loranger et al., 1985) \\
\hline Viroidin & 1.0 & & & & Intraperitoneal & (Loranger et al., 1985) \\
\hline Deoxoviroisin & 5.1 & & & & Intraperitoneal & (Loranger et al., 1985) \\
\hline
\end{tabular}

a Values given in $\mathrm{mg} / \mathrm{kg}$.

The liver is the primary target organ of toxicity of amatoxins, and hepatocellular effects represent the most lethal and the least treatable manifestation of that toxicity (Karlson-Stiber and Persson, 2003). In fact, due to the gastrointestinal absorption of amatoxins, it is expected that the liver is the first organ to enter in contact with a large amount of those toxins. Amatoxins accumulate in the liver upon uptake via OATP located in the sinusoidal membrane of hepatocytes (Fig. 4). Letschert et al. (2006) identified OATP1B3 as the main human uptake transporter for amatoxins. Amatoxins were analyzed in the liver following 2 fatal intoxications and in the liver of 2 patients who underwent liver transplantation, showing that high levels of amatoxins levels $[\alpha$-amanitin ranged from not detected to $19 \mathrm{ng} / \mathrm{g} ; \beta$-amanitin ranged from not detected to 3298 $\mathrm{ng} / \mathrm{g}$ (the method limit detection is $5 \mathrm{ng} / \mathrm{mL}$ )] (Jaeger et al., 1993).

Amatoxins do not undergo metabolism and they are excreted in large quantities in the urine during the first days following ingestion, with maximal excretion occurring in the first $72 \mathrm{~h}$ (Jaeger et al., 1993). A small amount can be eliminated in bile and may be reabsorbed via the enterohepatic circulation, which prolongs the body burden to these toxins (Faulstich et al., 1985). Intestinal elimination also seems to occur. In a human intoxication report (Jaeger et al., 1993) $6.3 \mathrm{mg}$ of $\alpha$-amanitin was eliminated in the feces over a period of $24 \mathrm{~h}$; this amount is believed to be lethal in an adult.

Possibly due to the preferential elimination route through the kidney, nephrotoxicity has also been reported (Mydlik and Derzsiova, 2006). The concentration found in the kidney has been shown to be 6 to 90 times higher than in the liver (Jaeger et al., 1993). Moreover, our group has performed an in vivo study (Wistar rats) with different $\alpha$-amanitin doses (10 and $21.4 \mathrm{mg} / \mathrm{kg}$, i.p.) and sacrifice times ( 2 and $4 \mathrm{~h}$ ). The results showed higher levels of total $\alpha$-amanitin in the kidney than in the liver (Garcia et al., 2015a). Therefore, although classically amatoxins are considered hepatic toxins, putative renal failure has to be evaluated.

\subsubsection{Clinical toxicology}

The symptomatology of amatoxin poisoning can extend from a simple gastroenterological disorder to death. Signs and symptoms of $\alpha$-amanitin poisoning are mainly attributable to the accumulation of $\alpha$-amanitin in the liver and kidneys (Mydlik and Derzsiova, 2006). Hepatic and renal injury does not cause symptoms until extensive damage has occurred. Thus, it is expected that the amatoxins clinical symptomatology becomes evident only several hours or even days after $A$. phalloides ingestion.

Three distinct phases of the A. phalloides toxic syndrome have been established in the literature: 1) gastrointestinal phase, 2) latent period and 3) the hepatorenal phase (Karlson-Stiber and Persson, 2003).

The first stage of A. phalloides syndrome occurs abruptly, 6$24 \mathrm{~h}$ after ingestion, and is characterized by nausea, vomiting, diarrhea (occasionally bloody), abdominal pain, and hematuria (Becker et al., 1976). This phase usually lasts about 12-36 h. Fever, tachycardia, metabolic disorders like hypoglycemia, dehydration, and electrolyte imbalance may occur during this phase (Barceloux, 2008). It has been suggested that gastrointestinal phase manifested after $A$. phalloides ingestion is due to the presence of phallotoxins in these mushrooms (Santi et al., 2012). However, the mechanism by which phallotoxins cause gastrointestinal symptoms remains to be elucidated.

The latent period is characterized by absence of symptoms, whilst progressive deterioration of hepatic and renal function is occurring (Becker et al., 1976). Hepatic lesions are accompanied by increased serum concentration of aspartate aminotransferase (AST), alanine aminotransferase (ALT), and lactate dehydrogenase (LDH) (Faulstich, 1979). The blood coagulation is also severely disturbed, which may give rise to internal bleeding (Amini et al., 2011).

The pathological hallmark of amatoxin poisoning is the development of liver necrosis and this characterizes the hepatorenal phase. The patients progressively lose kidney and liver functions and may develop jaundice, hypoglycemia, oliguria, delirium, and confusion (Becker et al., 1976). This phase culminates in rapid deterioration of central nervous system, severe hemorrhagic manifestations, renal and hepatic failure, which corresponds to a bad prognosis (Bonnet and Basson, 2002). About 20-79\% of the intoxicated patients develop chronic liver disease (Serne et al., 1996). 


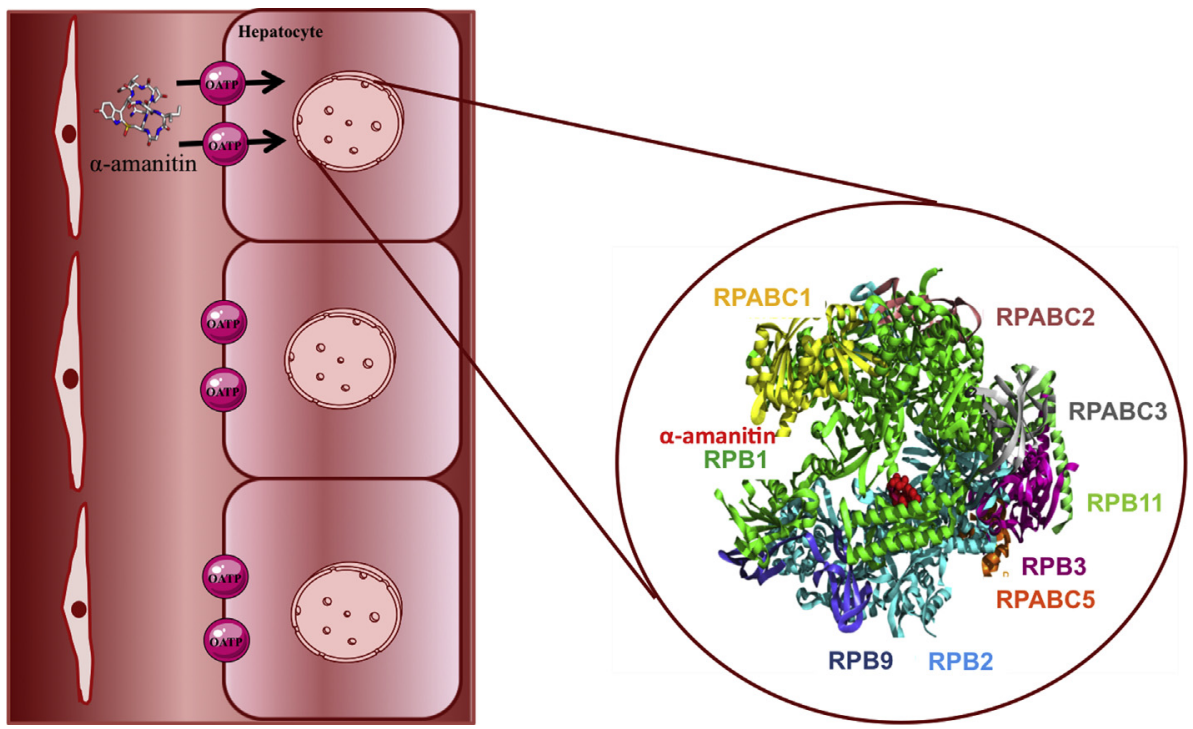

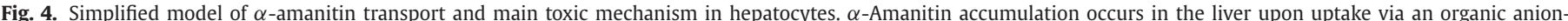

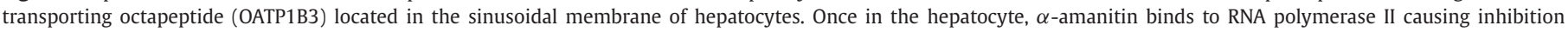
of its activity. The $\alpha$-amanitin binding site is located in the interface of Rpb1and Rpb2 subunits.

\subsubsection{Mechanisms of toxicity induced by amatoxins}

There are significant inter and intraspecies variations, concerning the concentration of amatoxins in mushrooms. Therefore, an accurate prediction of toxicity based on the amount of mushrooms consumed is difficult (Barceloux, 2008). The lethal dose of amatoxins in humans has been estimated (from accidental intoxications) to be about $0.1 \mathrm{mg} / \mathrm{kg}$ body weight (Table 2), or even lower, and this amount may be present in a single mushroom (Karlson-Stiber and Persson, 2003).

Several toxicity mechanisms have been attributed to amatoxins. The main mechanism seems to be their known ability to noncovalently bind and inhibit RNA polymerase II (RNAP II) activity in the nucleus (Wieland, 1983) (Fig. 5). Many experimental studies have been conducted to get a better understanding of the interaction with RNAP II (Cochet-Meilhac and Chambon, 1974; Nguyen et al., 1996; Rudd and Luse, 1996). Cochet-Meilhac and Chambon carried out a kinetic study to evaluate the interaction of amatoxins with RNAP II (Cochet-Meilhac and Chambon, 1974). The authors used purified calf thymus RNAP II and observed that the equilibrium association constant is high, ranging $10^{8}-10^{10}$ (CochetMeilhac and Chambon, 1974). Bushnell et al. obtained the first Xray elucidating the RNAP II $/ \alpha$-amanitin interactions. In this structure, the $\alpha$-amanitin binding site was located in the interface of subunits Rpb1 and Rpb2 (Bushnell et al., 2002). Moreover, the Xray structure characterization allowed to partially elucidate the key molecular contacts that contribute to RNAP II inhibition. RNAP II residues that interact with $\alpha$-amanitin are located entirely in the bridge helix (Bushnell et al., 2002). In particular, $\alpha$-amanitin binds directly to the bridge helix residue Glu822, through a hydrogen bond, and indirectly to the bridge helix residue His816 (Fig. 5) (Bushnell et al., 2002). However, it has been also proposed that $\alpha$-amanitin inhibits RNAP II by direct interference with the trigger loop (structural element that makes direct substrate contacts and promotes nucleotide addition) (Kaplan et al., 2008), therefore preventing the conformational change of RNAP II and inhibiting the ribonucleic acid (RNA) elongation process (Wang et al., 2006). In a recent in silico study, we showed that $\alpha$-amanitin interferes with the bridge helix and trigger loop (Garcia et al., 2014), which alters the elongation process and contributes to the inhibition of messenger RNA (mRNA) synthesis.
The decline of mRNA levels leads to the decrease of protein synthesis and, ultimately, to cell death (Wieland, 1983). Moreover, Nguyen et al. (1996) suggested that the binding of $\alpha$-amanitin to RNAP II results in the degradation of Rpb1 subunit. The authors have found, in mice fibroblasts, that $\alpha$-amanitin promotes the degradation of the Rpb1 subunit, resulting in its irreversible inhibition (Nguyen et al., 1996). However, the characterization of this mechanism needs further investigation.

In vitro studies have shown that apoptosis may play an important role in $\alpha$-amanitin-induced severe liver injury as observed in dog primary hepatocytes (Magdalan et al., 2010b) and in human hepatocyte cultures (Magdalan et al., 2010a, 2011). The exposure of hepatocytes to $\alpha$-amanitin ( $2 \mu \mathrm{M}$ ) resulted in p53-and caspase3-dependent apoptosis (Fig. 6) (Magdalan et al., 2011). In neonatal human diploid fibroblasts, $\alpha$-amanitin $(2 \mu \mathrm{g} / \mathrm{mL})$ treatment for $24 \mathrm{~h}$ resulted in a marked induction of $\mathrm{p} 53$. The concentration required for induction of p53 was correlated with the concentration required to inhibit mRNA synthesis, suggesting a link between these two effects (Ljungman et al., 1999). To further evaluate the role of p53 in transcription inhibition-mediated cell death, p53 knock-out HTC116 cells, and wild-type cells were treated with $\alpha$ amanitin $(10 \mu \mathrm{g} / \mathrm{ml})$ for $24 \mathrm{~h}$ and the extent of apoptosis was evaluated. The results showed that the knock-out p53 cells were less sensitive to death induced by $\alpha$-amanitin, corroborating that p53 plays an important role in $\alpha$-amanitin-induced toxicity. A stress signal is elicited by $\alpha$-amanitin, which leads to the translocation of cytoplasmic p53 to mitochondria and an alteration of mitochondrial membrane permeability through formation of p53 complexes with protective proteins (Bcl- $\mathrm{X}_{\mathrm{L}}$ and $\mathrm{Bcl}-2$ ) (Fig. 6). The complexes formation results in the release of cytochrome $c$ into the cytosol and the prosecution of the intrinsic apoptotic pathway (Fig. 6) (Arima et al., 2005). These results were further corroborated in vivo. Knockout p53/BAK mice showed marked resistance towards $\alpha$-amanitin ( $5 \mu \mathrm{g} / \mathrm{g}$ )-induced liver damage, while wild-type mice in the same conditions underwent organ destruction (Leu and George, 2007). An interaction between p53 and mitochondrial BAK seems to be important for p53's mitochondrial role in the induction of apoptosis by $\alpha$-amanitin (Leu and George, 2007).

Other mechanisms might be involved in $\alpha$-amanitin-induced toxicity. It has been suggested that TNF- $\alpha$ exacerbates $\alpha$-amanitin- 


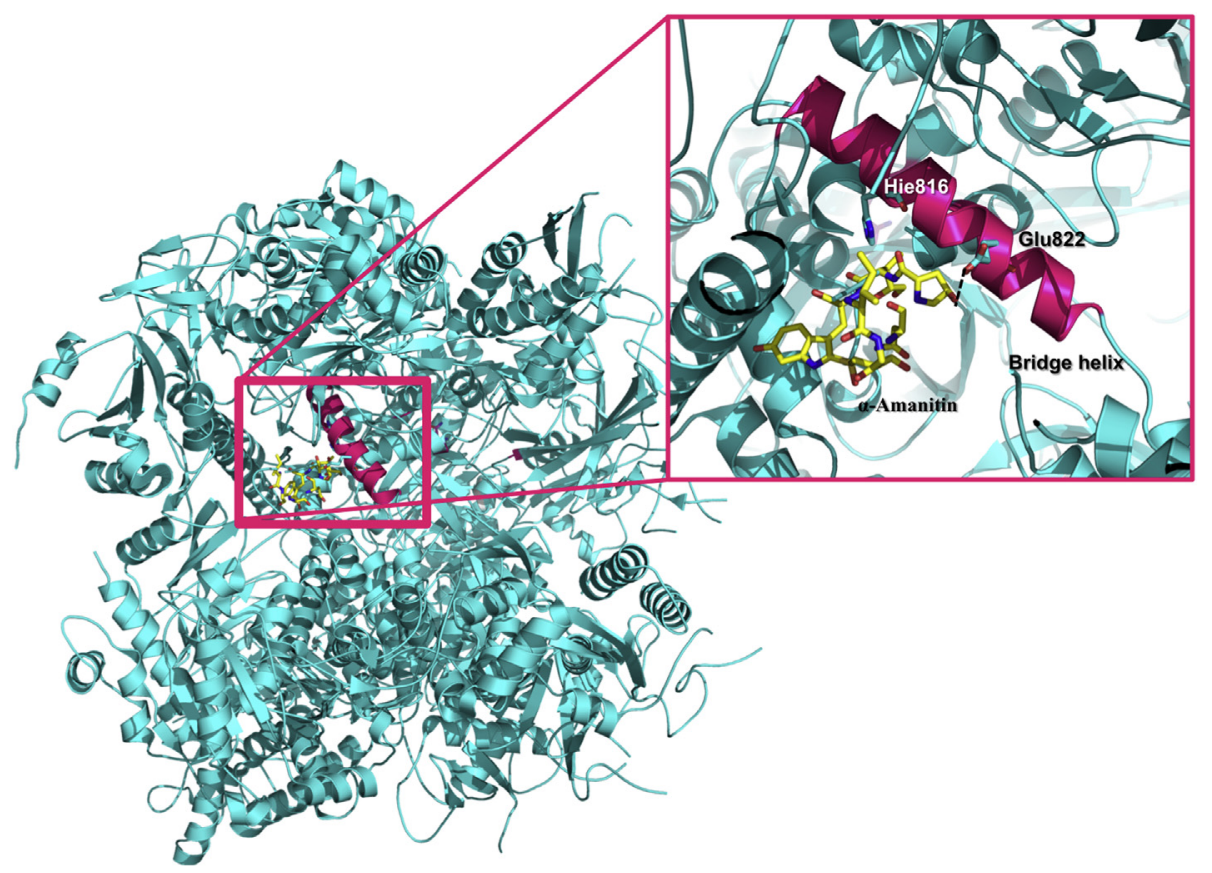

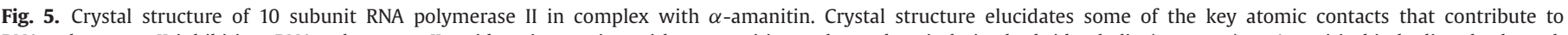

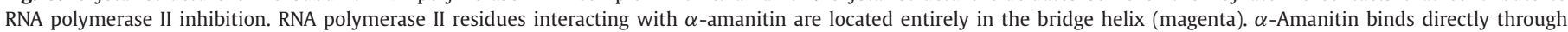

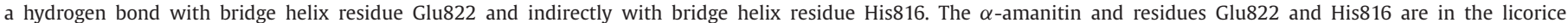
representation.

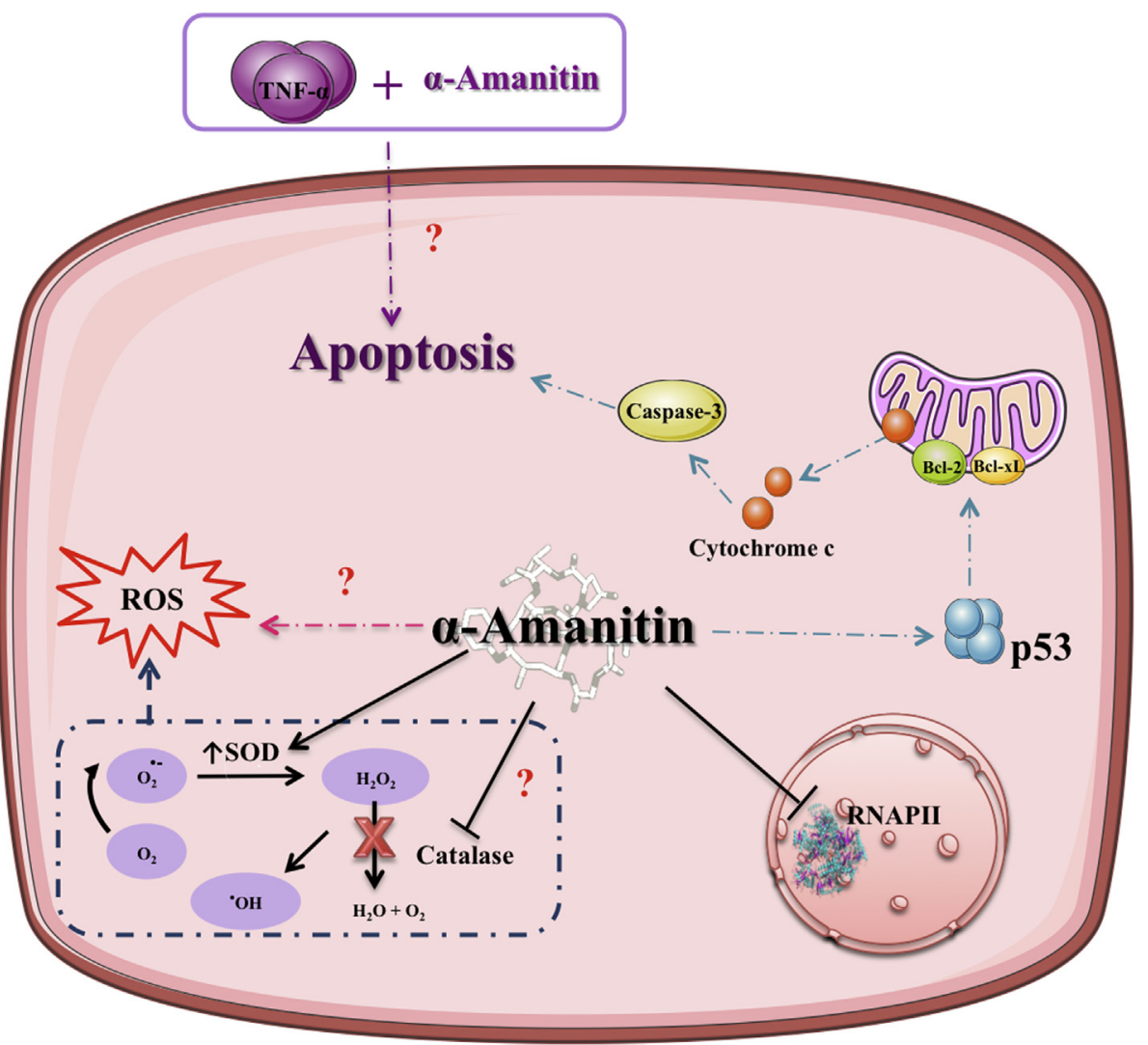

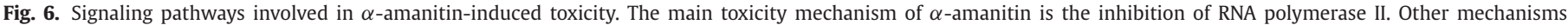

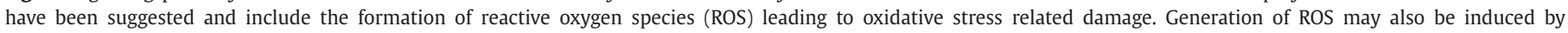

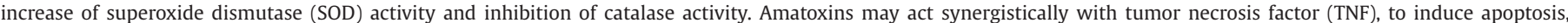

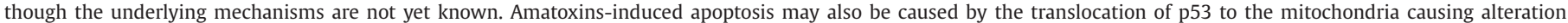

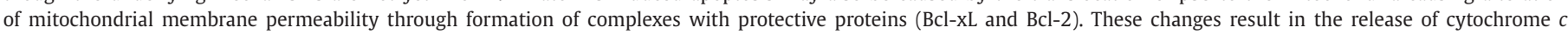
into the cytosol and activation of the intrinsic pathway of apoptosis. Question marks indicate that the mechanisms that remain unknown. 
induced hepatotoxicity in vivo (Fig. 6) (Leist et al., 1997). After in vivo administration of a high dose of $\alpha$-amanitin, hepatic TNF-mRNA was increased and hepatocytes underwent apoptosis, whereas in mice treated with anti-TNF antibodies, liver injury caused by $\alpha$-amanitin was prevented (Leist et al., 1997). In addition, transgenic mice lacking the 55 kDA TNF- $\alpha$ receptor seem to be relatively resistant to $\alpha$-amanitin-induced toxicity (Leist et al., 1997). Therefore, hepatocyte apoptosis may result from a synergistic action between $\alpha$-amanitin and TNF- $\alpha$ (Fig. 6) (Leist et al., 1997). However, the mechanisms of such synergistic effects remain unclear at this point and the dependence of $\alpha$-amanitin toxicity on the presence of TNF- $\alpha$ was not confirmed in another study using rat hepatocyte cultures (El-Bahay et al., 1999). Thus, TNF- $\alpha$ may not be indispensable for the development of cytotoxicity by $\alpha$-amanitin but exacerbates it. Actually, TNF- $\alpha$ co-treatment significantly increased lipid peroxidation caused by $\alpha$-amanitin and this effect was prevented by silybin, indicating the possible involvement of reactive oxygen species (ROS) (El-Bahay et al., 1999). These results suggest that TNF- $\alpha$ induced toxicity is linked with ROS production (El-Bahay et al., 1999). In fact, oxidative stress has also been postulated to be important in the development of severe hepatotoxicity in other studies (Fig. 6) (Zheleva, 2013; Zheleva et al., 2007). In vivo, hepatic accumulation of $\alpha$-amanitin leads to an increase of superoxide dismutase (SOD) activity and malondialdehyde products, and also results in the decrease of catalase activity (Fig. 6) (Zheleva et al., 2007). Lipid peroxidation may contribute to massive necrosis and severe hepatotoxicity (Zheleva et al., 2007). Zheleva (2013), using the electron paramagnetic resonance spin trapping technique, studied the in vitro and in vivo oxidation of $\alpha$-amanitin. During in vitro oxidation, $\alpha$-amanitin by itself can form unstable phenoxyl radicals. Using the same technique, these authors found that the production of reactive species increased in mice kidney subjected to an intraperitoneal administration of $1 \mathrm{mg} / \mathrm{kg}$ of $\alpha$-amanitin. Thus, $\alpha$-amanitin is able to form phenoxyl free radicals that might be involved in ROS generation (Fig. 6) (Zheleva, 2013). More investigation is needed to completely clarify the pathophysiology of ROS in the $\alpha$-amanitininduced toxicity, as it has been a scarcely studied subject.

\subsubsection{Pathophysiology of intoxications by amatoxins}

2.6.4.1. Liver. As previously mentioned, the main pathophysiologic feature of the intoxication by amatoxins is liver failure. Histopathological findings in liver biopsy specimens have shown massive centrilobular hepatic necrosis (Pond et al., 1986). Acute toxic hepatitis may develop rapidly, then reaching the state of liver insufficiency, and ultimately coma (Mydlik and Derzsiova, 2006). Five autopsies were performed on patients fatally poisoned with $A$. phalloides (Fineschi et al., 1996). Those autopsies revealed intensely yellow liver of creamy consistency and diffuse subcapsular hemorrhage. The histological examination confirmed stasis in all organs, including liver with diffuse hemorrhagic foci. The liver showed typical features of massive centrilobular necrosis and vacuolar degeneration of hepatocytes (Fineschi et al., 1996). Pathological examinations were also performed in two explanted liver after amatoxin poisoning. The cut surface of the explanted livers was hemorrhagic and had a nutmeg appearance. Centrilobular massive hemorrhagic necrosis and fatty degeneration areas were also observed (Kucuk et al., 2005).

Liver failure can lead to disseminated intravascular coagulation due to reduced clearance of activated clotting factors, release of pro-coagulants from damaged hepatocytes and reduced synthesis of coagulation inhibitors, contributing to multi-organ failure (Sanz et al., 1988; Soysal et al., 2006). Further consumption and subsequent exhaustion of coagulation proteins and platelets (from ongoing activation of coagulation) may culminate in severe bleeding (Sanz et al., 1988; Soysal et al., 2006).
2.6.4.2. Kidney. Nephrotoxicity after A. phalloides poisoning is also frequent. Patients can develop acute tubular necrosis with kidney failure (Mydlik and Derzsiova, 2006). Post-mortem examinations of patients after amatoxin poisoning showed dark red kidneys with extravasation of blood, especially in the cortical region. Stasis with diffuse hemorrhagic foci, acute tubular necrosis, and massive quantities of hyaline casts in the tubules were also found in patients that died after $A$. phalloides intoxication (Fineschi et al., 1996). Fanconi-type renal tubular acidosis associated with A. phalloides ingestion has also been reported (Barceloux, 2008).

2.6.4.3. Central nervous system. Neurologic manifestations, either primary due to the accumulation of ammonia or secondary due to multi-organ failure combined with hypotension, may develop in response to abnormal liver and kidney functions (Barceloux, 2008). Ammonia, a by-product of protein metabolism, is neurotoxic at high concentrations (Ytrebo et al., 2006). The liver converts ammonia to urea, which is excreted through the kidneys. Amatoxinintoxicated patients with continued loss of hepatocellular function are not able to transform ammonia to urea. Blood ammonia levels rise and ammonia is delivered to the brain causing encephalopathy, disorientation, confusion, lethargy, somnolence, vertigo, convulsions, and coma (Bonnet and Basson, 2002).

\subsubsection{Treatment and management of intoxications by amatoxins}

General treatment measures applied to amatoxins' poisoned patients include: stabilization of vital functions, intensive and supportive measures, prevention of the poison absorption, extensive hydration through i.v. route to protect kidneys and increase the elimination of amatoxins, use of putative antidotes, enhanced elimination of the poison and prevention of complications (Diaz, 2005b). Some of these measures have shown some degree of success, while others show negligible efficacy (Table 3). At this point, it can be said that a lot of research work still needs to be done to achieve a satisfactory therapeutic efficacy against amatoxins intoxication.

2.6.5.1. Dealing with intoxication cases. On a putative case of amatoxins intoxication, the initial step is to take the clinical history of the patient and perform stabilizing measures, if required. Fluid and electrolyte imbalance may occur in the gastrointestinal phase or result from measures undertaken to eliminate the amatoxins. Intravenous fluids may have to be given for extra-fluid and electrolyte replacement with careful monitoring of clinical biochemical levels (Faulstich, 1979). The effects of amatoxins on protein synthesis and the damage on liver cells will cause alteration on coagulation factors (Faulstich, 1979), therefore optimal treatment includes intravenous vitamin $\mathrm{K}$ and fresh-frozen plasma (Alves et al., 2001). Liver damage should be assessed promptly as it allows determining how far is the damage caused and the best clinical actions to assume. Laboratory evaluation should include liver and kidney function, testing aminotransferases, prothrombin time, blood urea nitrogen, creatinine, ammonia, fibrinogen, bilirubin, complete blood count, electrolyte analysis, amylase, lipase, and urinalysis (Diaz, 2005a).

All the basic information, such as the amount, type (a sample of the ingested mushroom is of outmost importance), time of mushrooms ingestion, the first evidence of symptoms, and the symptoms present at the moment of hospitalization are of great value in the first contact with the possible amatoxins' poisoned patient. The time between ingestion and onset of symptoms is critical. Sudden onset of intense gastrointestinal symptoms after a delay of 6$24 \mathrm{~h}$, following a mushrooms meal, should raise the suspicion of amatoxin poisoning. 
Table 3

Summary of clinical therapy in amatoxins poisoning.

\begin{tabular}{|c|c|c|c|c|c|c|c|c|}
\hline Cases & Years & Country & Drug therapy & $\begin{array}{l}\text { Prevention of amatoxins } \\
\text { absorption }\end{array}$ & $\begin{array}{l}\text { Elimination of absorbed } \\
\text { amatoxins }\end{array}$ & $\begin{array}{l}\text { Liver } \\
\text { transplantation }\end{array}$ & $\begin{array}{l}\text { Mortality rate } \\
(\%)\end{array}$ & References \\
\hline 47 & $\begin{array}{l}1971 \\
-1975\end{array}$ & Italy & BPC & & & & 4.0 & Moroni et al. (1976) \\
\hline 205 & $\begin{array}{l}1971 \\
-1980\end{array}$ & $\begin{array}{l}6 \text { European } \\
\text { countries }\end{array}$ & $\mathrm{BPC}+\mathrm{SLB}$ & & & & 22.4 & $\begin{array}{l}\text { Floersheim et al. } \\
\text { (1982) }\end{array}$ \\
\hline 2 & $\begin{array}{l}1980 \\
-1981\end{array}$ & Austria & SLB & & & & 0.0 & Hruby et al. (1983) \\
\hline 16 & $\begin{array}{l}1980 \\
-1981\end{array}$ & Austria & $\mathrm{BPC}+\mathrm{SLB}$ & & & & 6.25 & Hruby et al. (1983) \\
\hline 44 & 1981 & Italy & BPC & AC & & & 9.1 & $\begin{array}{l}\text { Fantozzi et al. } \\
\text { (1986) }\end{array}$ \\
\hline 43 & $\begin{array}{l}1984 \\
-1989\end{array}$ & France & $\mathrm{BPC}+\mathrm{SLB}$ & & & 2 & 17.8 & Jaeger et al. (1993) \\
\hline 4 & 1994 & New York & BPC & AC & & & 25 & $\begin{array}{l}\text { Feinfeld et al. } \\
\text { (1994) }\end{array}$ \\
\hline 21 & $\begin{array}{l}1984 \\
-1993\end{array}$ & Germany & $\mathrm{BPC}+\mathrm{SLB}$ & & PL & & 4.8 & Jander et al. (2000) \\
\hline 2 & 2000 & Portugal & $\mathrm{BPC}+\mathrm{SLB}$ & $A C$ & & & 0.0 & Alves et al. (2001) \\
\hline 2 & 2000 & Portugal & $\mathrm{BPC}+\mathrm{SLB}$ & $A C$ & PL & 2 & 0.0 & Alves et al. (2001) \\
\hline 103 & $\begin{array}{l}1971 \\
-1995\end{array}$ & Slovak Republic & BPC & & HP, HD & & 7.8 & $\begin{array}{l}\text { Enjalbert et al. } \\
\text { (2002) }\end{array}$ \\
\hline 18 & 1988 & Croatia & BPC & & FD, HD, PL & & 22.2 & $\begin{array}{l}\text { Enjalbert et al. } \\
\text { (2002) }\end{array}$ \\
\hline 86 & $\begin{array}{l}1987 \\
-1993\end{array}$ & Italy & NAC & & & & 7.0 & $\begin{array}{l}\text { Enjalbert et al. } \\
\text { (2002) }\end{array}$ \\
\hline 25 & $\begin{array}{l}1980 \\
-1986\end{array}$ & Europe & SLB & & FD, HP, HD & & 4.0 & $\begin{array}{l}\text { Enjalbert et al. } \\
(2002)\end{array}$ \\
\hline 20 & $\begin{array}{l}1991 \\
-1999\end{array}$ & Slovak Republic & SLB & & FD, HP, HD & & 0.0 & $\begin{array}{l}\text { Enjalbert et al. } \\
\text { (2002) }\end{array}$ \\
\hline 26 & 1993 & Germany & SLB & & & & 0.0 & $\begin{array}{l}\text { Enjalbert et al. } \\
\text { (2002) }\end{array}$ \\
\hline 1 & $\begin{array}{l}2000 \\
-2004\end{array}$ & Czech Republic & $\mathrm{BPC}+\mathrm{SLB}$ & AC & HD & & 0.0 & $\begin{array}{l}\text { Krenova et al. } \\
\text { (2007) }\end{array}$ \\
\hline 2 & $\begin{array}{l}2000 \\
-2004\end{array}$ & Czech Republic & $\mathrm{BPC}+\mathrm{SLB}$ & $\mathrm{AC}, \mathrm{GL}$ & HP & & 0.0 & $\begin{array}{l}\text { Krenova et al. } \\
\text { (2007) }\end{array}$ \\
\hline 1 & $\begin{array}{l}2000 \\
-2004\end{array}$ & Czech Republic & $\mathrm{BPC}+\mathrm{SLB}$ & $\mathrm{AC}, \mathrm{GL}, \mathrm{FD}$ & & 1 & 100 & $\begin{array}{l}\text { Krenova et al. } \\
\text { (2007) }\end{array}$ \\
\hline 2 & $\begin{array}{l}2000 \\
-2004\end{array}$ & Czech Republic & BPC & FD & & & 0.0 & $\begin{array}{l}\text { Krenova et al. } \\
\text { (2007) }\end{array}$ \\
\hline 2 & $\begin{array}{l}2000 \\
-2004\end{array}$ & Czech Republic & BPC & GL, AC & & & 0.0 & $\begin{array}{l}\text { Krenova et al. } \\
\text { (2007) }\end{array}$ \\
\hline 2 & $\begin{array}{l}2000 \\
-2004\end{array}$ & Czech Republic & BPC & GL, AC & HP & & 0.0 & $\begin{array}{l}\text { Krenova et al. } \\
\text { (2007) }\end{array}$ \\
\hline 1 & $\begin{array}{l}200 \\
-2004\end{array}$ & Czech Republic & BPC & GL & & & 100 & $\begin{array}{l}\text { Krenova et al. } \\
\text { (2007) }\end{array}$ \\
\hline 111 & $\begin{array}{l}1988 \\
-2002\end{array}$ & Italy & BPC & $\mathrm{AC}$ & & & 1.8 & $\begin{array}{l}\text { Giannini et al. } \\
\text { (2007) }\end{array}$ \\
\hline 28 & $\begin{array}{l}1983 \\
-1992\end{array}$ & NS & SLB & & & & 4.0 & Mengs et al. (2012) \\
\hline 126 & $\begin{array}{l}1983 \\
-1992\end{array}$ & NS & $\mathrm{SLB}+\mathrm{BPC}$ & & & & 11.0 & Mengs et al. (2012) \\
\hline 118 & $\begin{array}{l}1957 \\
-2005\end{array}$ & NS & SLB & & & & 5.1 & Mengs et al. (2012) \\
\hline 249 & $\begin{array}{l}1957 \\
-2005\end{array}$ & NS & $\mathrm{SLB}+\mathrm{BPC}$ & & & & 8.8 & Mengs et al. (2012) \\
\hline 77 & 2008 & Turkey & $\mathrm{BPC}+\mathrm{SLB}+\mathrm{NAC}$ & AC, GL & $\mathrm{HF}$ & 1 & 2.5 & $\begin{array}{l}\text { Ahishali et al. } \\
\text { (2012) }\end{array}$ \\
\hline 2 & 2009 & Massachusetts & $\mathrm{BPC}+\mathrm{SLB}+\mathrm{NAC}$ & $\mathrm{AC}$ & & & 0.0 & Ward et al. (2013) \\
\hline 2 & $\begin{array}{l}1999 \\
-2012\end{array}$ & Australia & $\mathrm{BPC}+\mathrm{SLB}+\mathrm{NAC}$ & AC & & & 0.0 & $\begin{array}{l}\text { Roberts et al. } \\
\text { (2013) }\end{array}$ \\
\hline 2 & $\begin{array}{l}1999 \\
-2012\end{array}$ & Australia & $\mathrm{BPC}+\mathrm{SLB}$ & & & & 50 & $\begin{array}{l}\text { Roberts et al. } \\
\text { (2013) }\end{array}$ \\
\hline 5 & $\begin{array}{l}1999 \\
-2012\end{array}$ & Australia & $\mathrm{SLB}+\mathrm{NAC}$ & $\mathrm{AC}$ & & & 40 & $\begin{array}{l}\text { Roberts et al. } \\
\text { (2013) }\end{array}$ \\
\hline 24 & $\begin{array}{l}2001 \\
-2006\end{array}$ & Turkey & $\mathrm{BPC}+\mathrm{NAC}$ & AC, GL & HP & & 4.4 & Akin et al. (2013) \\
\hline 16 & $\begin{array}{l}2001 \\
-2006\end{array}$ & Turkey & BPC & $A C, G L$ & HP & & 18.7 & Akin et al. (2013) \\
\hline
\end{tabular}

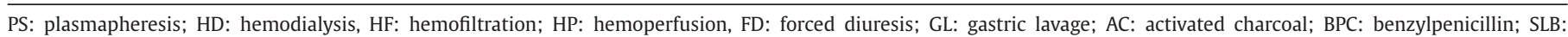
silybin; NAC: N-acetylcysteine; NS: not specified. 
2.6.5.1.1. Identification of amatoxins and phallotoxins. If A. phalloides-type mushrooms ingestion is plausible, gastric content, mushroom samples, and stool specimens, if available, should be analyzed to verify the presence of amatoxins and phallotoxins (Becker et al., 1976). Several methods can be used for identification and quantification of amatoxins and phallotoxins in the specimens of $A$. phalloides. Evaluation of these toxins in mushrooms has been performed using reversed-phase high-performance liquid chromatography (RP-HPLC) (Enjalbert et al., 1996, 2004, 1999, 1993, 1992; Garcia et al., 2015c; Hu et al., 2012), capillary electrophoresis coupled to mass spectrometry (MS) (Rittgen et al., 2008), liquid chromatography (LC) coupled to MS or to tandem MS (Chung et al., 2007; Garcia et al., 2015c; Jansson et al., 2012) and LC electrospray ionization time-of-flight-MS (LC/ESI-TOF-MS) (Ahmed et al., 2010). RP-HPLC is the most commonly used method, although the LC-MS method seems to provide the most reliable and sensitive results.

The Meixner test can also be used if a specimen of the ingested mushroom is available for analysis (Bleuter and Vergeer, 1980). The test is based on an acid-catalyzed (using concentrated hydrochloric acid) reaction of amatoxins with the complex biopolymer lignin to form a blue product. As described by Meixner, the test is run by squeezing the juice from a piece of fresh mushroom tissue onto a piece of newsprint, which contains lignin, allowing the spot to dry, and then applying one drop of concentrated hydrochloric acid. Formation of a blue color indicates a positive test (Bleuter and Vergeer, 1980). Nevertheless, the efficacy of this test is limited by false positive results. Mushrooms containing hydroxyl-substituted tryptamine compounds, such as psilocin or serotonin may also produce a positive Meixner reaction (Beuhler et al., 2004), and therefore a positive test result requires further confirmation of the mushroom identity.

A rapid and sensitive method that can be performed in the patient bed side, or within minutes in the hospital structures, would be of outmost value for a better clinical assessment but it is not available presently. Urine analysis is a vital tool for amatoxin poisoning surveillance, contributing to the management of suspected mushroom poisoning (Butera et al., 2004). If analysis is performed within 36 h of ingestion, $\alpha$-amanitin can be detected in urine. After $36 \mathrm{~h}$, the analysis is unreliable and a negative result cannot rule out poisoning (Karlson-Stiber and Persson, 2003). There are different methods for urine analysis: radioimmunoassay, Enzyme Linked Immunosorbent Assay (ELISA) and HPLC (Barceloux, 2008).

2.6.5.1.2. Minimizing absorption and inactivation of amatoxins in the gastrointestinal tract. After careful consideration of the risks to the intoxicated patient, gastrointestinal (GI) decontamination should be considered based upon the time elapsed from ingestion to time of presentation at the hospital. Several methods of GI decontamination that can be used alone or in combination include gastric lavage, whole bowel irrigation, administration of activated charcoal, and endoscopic or surgical removal of the ingested poison (Albertson et al., 2011; Garcia et al., 2015b). Whole bowel irrigation has a very limited impact in the treatment of human poisoning, and therefore should not be used routinely in the management of the poisoned patient (Albertson et al., 2011; Santi et al., 2012; Seymour and Henry, 2001). Gastric lavage is most useful if attempted within $1 \mathrm{~h}$ after the ingestion of a potentially life threatening poison (Vale, 1997), while it is contraindicated in patients with loss of airway protective reflexes, such as in a patient with a depressed state of consciousness, and in patients who are at risk of hemorrhage or gastrointestinal perforation, as well as in patients that underwent recent surgery or have other medical conditions such as coagulopathy (Vale et al., 2004). Clinical toxicology database of the United Kingdom national poisons information service (TOXBASE) recommends gastric lavage up to $1 \mathrm{~h}$ after $A$. phalloides ingestion (TOXBASE, 2008).
Activated charcoal efficacy decreases with increased time elapsed after ingestion, while the greatest benefit can be observed within $1 \mathrm{~h}$ after ingestion of the poison (Albertson et al., 2011). The efficacy of activated charcoal was not yet proven in controlled clinical settings towards amatoxins ingestion, but activated charcoal (20-40 g every 3-4 h) has been administered routinely because it may also interrupt the enterohepatic circulation of amatoxins and potentially reduce their toxicity (Garcia et al., 2015b). The center of anti-poisoning information (CIAV) in Portugal and TOXBASE recommend a dose of $50 \mathrm{~g}$ every $4 \mathrm{~h}$ (CIAV, 2014; TOXBASE, 2008). If vomiting is troublesome, the dose can be reduced to $12.5 \mathrm{~g}$ charcoal hourly or $25 \mathrm{~g}$ every $2 \mathrm{~h}$ (TOXBASE, 2008). As most patients reach the hospital emergency hours after ingesting the mushrooms, these clinical measures have limited efficacy, although they are undertaken to assure the best clinical treatment available in a life risk situation, even before confirmation of amatoxin poisoning (Garcia et al., 2015b).

2.6.5.1.3. Elimination of absorbed amatoxins. As stated, excretion of amatoxins is mainly urinary; therefore diuresis would potentially increase the renal clearance and could be a potential good therapy for this intoxication. Forced diuresis is recommended, with urine output of $100-200 \mathrm{ml} / \mathrm{h}$ for $4-5$ days (Mas, 2005). This procedure is also recommended by CIAV and national poisons center of New Zealand, especially in the first $48 \mathrm{~h}$ after ingestion (CIAV, 2014; Toxinz, 2013).

Amatoxins are only detected in the plasma at the early phase of poisoning and only for a short period of time. For that reason, removing amatoxins by extracorporal elimination, particularly hemodialysis, hemoperfusion or plasmapheresis, was previously considered to have no impact on patient survival (Jaeger et al., 1993; Koppel, 1993). Some studies present some evidence demonstrating benefits of molecular adsorbent recirculating system (MARS) in management of $A$. phalloides poisonings (Lionte et al., 2005; Shi et al., 2002). However, these findings have not been adequately corroborated, since only very few case reports have been published and further evidence is needed. In a recent study, the effectiveness and safety of combined extracorporeal techniques using the fractionated plasma separation and adsorption system, FPSA, Prometheus ${ }^{\circledR} 4008 \mathrm{H}$, Fresenius Medical Care, Germany, in poisoned patients with A. phalloides was studied (Bergis et al., 2012). This technique consists on the elimination of the protein-bound and water-soluble toxin. Prometheus ${ }^{\circledR}$ seemed to be a promising treatment for $A$. phalloides poisoning by preventing the need for liver transplantation. However, such treatment was administered associated to other therapies (silybin and $\mathrm{N}$-acetylcysteine). MARS and Prometheus ${ }^{\circledR}$ are based in the same principle, the extracorporeal elimination of toxins. As amanitin is rapidly eliminated from plasma, these techniques may be useful if patients are presented to the hospital when the first symptoms appear not after" with "are based in the same principle, the extracorporeal liver support, however more clinical studies are needed to demonstrate its effectiveness.

2.6.5.2. Drug therapy. Based on pre-clinical findings, several treatments have been applied in intoxications by amatoxins, namely hormones (insulin, growth hormone, glucagon), steroids, vitamin C, vitamin E, cimetidine, $\alpha$-lipoic acid, antibiotics (benzylpenicillin, ceftazidime), N-acetylcysteine, and silybin (Enjalbert et al., 2002). From these, only benzylpenicillin, ceftazidime, N-acetylcysteine, and silybin were proven to have some degree of therapeutic efficacy, although the death rate remains extremely high (Poucheret et al., 2010) (Table 3). Some of the most used procedures that showed some clinical effectiveness are addressed below.

2.6.5.2.1. $\beta$-Lactam antibiotics. The most widely used drug in the management of amatoxin poisoning, in monotherapy or in combination with other agents is benzylpenicillin. One study in- 
volving 47 patients poisoned with $A$. phalloides demonstrated that benzylpenicillin combined with supportive measures was an effective treatment in 43 cases (Table 3) (Moroni et al., 1976). The effectiveness of benzylpenicillin was, also, evaluated in a retrospective study including 111 patients treated from 1988 to 2002 in the Toxicological Unit of Careggi General Hospital for amatoxin poisoning (Giannini et al., 2007). The administration of benzylpenicillin combined with intensive fluid and supportive therapy, restitution of the altered coagulation factors, multiple-dose activated charcoal, mannitol, dexamethasone and reduced glutathione (GSH) resulted in the complete recovery of all patients treated within $36 \mathrm{~h}$ after mushroom ingestion (Table 3) (Giannini et al., 2007). However, two patients admitted to the hospital more than $60 \mathrm{~h}$ after mushroom ingestion died (Table 3) (Giannini et al., 2007). On the other hand, benzylpenicillin monotherapy administered to 103 intoxicated patients resulted in an overall mortality of $7.8 \%$ (Table 3). Higher overall mortality (22.2\%) was observed in Croatia in a study that included 18 patients treated in 1988 (Table 3) (Enjalbert et al., 2002). Taken together, these results evidence that benzylpenicillin has some therapeutic effectiveness, although the high mortality rate indicates that this antidote is far from ideal (Table 3).

In vitro studies using human hepatocytes provided some evidence to support the effectiveness of benzylpenicillin in limiting the cytotoxicity of amatoxins (Magdalan et al., 2010a, 2009). In vivo studies, dogs (beagles, weighing 8-15 kg) were given an oral dose of lyophilized $A$. phalloides, which contained $0.14 \mathrm{mg} / \mathrm{g}$ of acid phallotoxins, $0.04 \mathrm{mg} / \mathrm{g}$ of acid amatoxins, $0.04 \mathrm{mg} / \mathrm{g}$ of neutral phallotoxins, and $1.1 \mathrm{mg} / \mathrm{g}$ of neutral amatoxins. Benzylpenicillin $(1000 \mathrm{mg} / \mathrm{kg})$ was intravenously given at $5 \mathrm{~h}$ after poisoning and silymarin $(50 \mathrm{mg} / \mathrm{kg}$ ) was intravenously given at $5 \mathrm{~h}$ followed by a dose of $30 \mathrm{mg} / \mathrm{kg}$ at $24 \mathrm{~h}$ after poisoning. The results showed that benzylpenicillin combined with silymarin helped prevent liver damage, since the increases observed on blood aminotransferases (ALT and AST) and also alkaline phosphatase levels induced by $A$. phalloides were inhibited (Floersheim et al., 1978). However, the effectiveness of benzylpenicillin (intraperitoneal dose of 1 million units $/ \mathrm{kg} /$ day administered at $4 \mathrm{~h}$ after poisoning) may be species dependent, as it was not found to be effective in limiting hepatic injury in mice (weighed an average of $42.4 \mathrm{~g}$ ) induced by a single intraperitoneal dose of $\alpha$-amanitin $(0.6 \mathrm{mg} / \mathrm{kg})$ (Tong et al., 2007). Dogs seem to be the model that closest resembles humans concerning intoxications by amatoxins, since the clinical course and symptoms are almost identical (Faulstich et al., 1985). Moreover, dogs and humans share a great oral bioavailability for amatoxins (Faulstich et al., 1985). Despite the scarce oral bioavailability in rodents, the toxic effects of amatoxins are similar to those found in humans (Kaya et al., 2014). Most studies with mice use intraperitoneal administration that could intensify the amatoxins-induced organ damage. In fact, that can explain the lack of efficacy of the antidotes in mice injected with high doses of amatoxins.

Several hypotheses have been proposed to explain the mechanisms of benzylpenicillin in amatoxin poisoning. It was previously thought that benzylpenicillin could displace $\alpha$-amanitin from albumin, allowing better renal elimination, but such hypothesis was later refuted by evidences demonstrating that $\alpha$-amanitin does not bind to serum albumin (Floersheim, 1983). The influence of benzylpenicillin on the hepatic uptake of amatoxins has also been studied but remains unclear. Kroncke et al. studied amatoxins hepatic transport in membrane vesicles from rat liver using radiolabeled $\alpha$ - and $\gamma$-amanitins (Kroncke et al., 1986). It was observed that amatoxin membrane transport was not inhibited by benzylpenicillin. However, recent in vitro findings, using human hepatocytes, suggest that benzylpenicillin blocks $\alpha$-amanitin uptake, being a potent inhibitor of OATP1B3 transporter (Letschert et al., 2006). Such putative protective effect requires further experimental in vivo confirmation.

Despite the reported efficacy of benzylpenicillin, this antidote has safety issues. The administration of benzylpenicillin may result in high sodium salt concentration in the body, which can disrupt electrolyte balance. In addition, it may cause allergic reactions, granulocytopenia, and evoke neurotoxic symptoms in patients with nervous system disease and renal insufficiency (Enjalbert et al., 2002).

Another $\beta$-lactam antibiotic used in the management of $A$. phalloides poisoning is ceftazidime. However, the number of amatoxin poisoning cases treated with ceftazidime is limited (Poucheret et al., 2010) and this antidote was always administered in combination with silybin (Enjalbert et al., 2002), which causes bias to its putative protective effect. Further investigations are needed to better understand the underlying protective mechanism of action of ceftazidime.

The Portuguese poisoning information center recommends a dose of benzylpenicillin of 1 million units/kg/day, by continuous intravenous infusion (CIAV, 2014) in amatoxin poisoning. This treatment should be maintained until clinical and laboratory improvement is achieved, as observed by serum transaminases levels and prothrombin time. TOXBASE recommends a dose of 0.5 million units $/ \mathrm{kg} /$ day as a continuous infusion for 2-3 days after the day of ingestion, with close monitoring of renal function (TOXBASE, 2008). However, the national poisons center of New Zealand does not recommend the use of benzylpenicillin (Toxinz, 2013) due to its safety issues and allergenic potential.

2.6.5.2.2. Silymarin. Silybum marianum ('milk thistle') is currently the most widely researched plant used in the treatment of liver diseases. The active constituents of milk thistle are flavonolignans including silybin, silydianin, and silychristine, collectively known as silymarin. Silybin is the component with the highest antioxidant activity, and 'milk thistle' extracts are usually standardized to contain 70-80\% silybin (Luper, 1998). Due to its antioxidant activity, silybin has been applied in the management of amatoxin poisoning and evidence on the effectiveness of silybin in poisoned patients has been reported. Forty-six cases of amatoxin poisoning treated with silybin as monotherapy showed that all patients survived (Table 3) (Enjalbert et al., 2002). These results indicate that silybin has some effectiveness in the management of amatoxin poisoning, exhibiting low mortality rates (Table 3). Silybin seems to be more effective as monotherapy than when combined with benzylpenicillin. In fact, in a recent study based on 1500 documented cases, it was concluded that the overall mortality in intoxicated patients with $A$. phalloides treated with silybin, as Legalon ${ }^{\circledR}$ SIL (silibinin-C-2',3-dihydrogen succinate, disodium salt), is less than $10 \%$ in comparison to more than $20 \%$ when using benzylpenicillin or a combination of silybin and benzylpenicillin (Mengs et al., 2012).

Cytotoxicity evaluation on cultured human hepatocyte using MTT reduction and leakage assays was performed after 12, 24 and $48 \mathrm{~h}$ exposure to $\alpha$-amanitin $(2 \mu \mathrm{M})$ and/or silybin. The treatment with silybin showed a strong protective effect against cell damage in $\alpha$-amanitin-induced toxicity (Magdalan et al., 2010a).

The protective effects of silymarin on amatoxin poisoning have also been studied in different animal models. Again, species differences were found, since a significant hepatoprotective effect was observed for silybin in $\alpha$-amanitin-induced liver damage in dogs (Vogel et al., 1984), while no protective effect was observed in mice (Tong et al., 2007). In both species, the $\alpha$-amanitin $\mathrm{LD}_{50}$ was administered; however different administration routes were used. $\alpha$-Amanitin was administered orally to dogs while in mice it was administered intraperitoneally. It is reasonable to consider that $\alpha$ amanitin-induced toxicity in mice could be enhanced by intraperitoneal administration and, in that case, the overall protection 
induced by silybin failed. Moreover, inter species differences may also exist.

As mentioned above, the postulated protective mechanisms of action mediated by silybin are associated to its strong antioxidant activity, which could explain its action against hepatotoxic agents that act through oxidative stress. Silybin and silymarin reduce the free radical load, stimulate the activity of SOD and increase GSH levels (Fraschini et al., 2002). Moreover, Pradhan and Girish (2006) suggest that silymarin is able to enter the nucleus and specifically stimulate RNA polymerase I activity. This effect increases the transcription of ribosomal RNA, which may counterbalance the inhibition of RNAP II induced by amatoxins (Pradhan and Girish, 2006). Nevertheless, this hypothesis needs further confirmation. Another important effect of silybin is the inhibition of the organic aniontransporting polypeptides (OATPs) (Wlcek et al., 2013), which may prove to be crutial to prevent the uptake of amanitin by hepatocytes.

Based on animal studies and limited human data, it seems that silybin has been the most promising molecule to prevent pathophysiological events after amatoxin intoxications, with a good safety profile. Therefore, CIAV and the national poisons center of New Zealand recommend an intravenous administration of 20$50 \mathrm{mg} / \mathrm{kg} /$ day in four divided doses. Treatment should be continued for 48-96 h after mushroom ingestion (CIAV, 2014; Toxinz, 2013). TOXBASE recommendations for $A$. phalloides poisoning treatment do not include silybin administration (TOXBASE, 2008) probably due to the low clinical evidence available so far concerning silybin efficacy.

2.6.5.2.3. N-acetylcysteine. N-acetylcysteine has been in medical use for more than 50 years as a mucolytic agent. It is also a well-known treatment for acetaminophen overdose, and related liver damage (James et al., 2003). Due to the clinical similarity between acetaminophen overdose and amatoxin poisoning, both leading to hepatic and renal necrosis, $\mathrm{N}$-acetylcysteine has been applied in the management of amatoxins poisoning. This compound is a precursor of GSH and due to its antioxidant and liver protecting effects it is postulated to play a protective role in patients poisoned with $A$. phalloides. $\mathrm{N}$-acetylcysteine, administered to 86 amatoxins poisoned patients showed overall survival of 93.0\% (Table 3) (Enjalbert et al., 2002). A retrospective multidimensional multivariate statistical analysis of 2110 clinical cases of amatoxin poisoning was performed in order to optimize therapeutic decision-making (Poucheret et al., 2010). The results of this study showed that $\mathrm{N}$-acetylcysteine has a statistically positive impact on amatoxin poisoning (Poucheret et al., 2010). A retrospective study including 40 amatoxins-intoxicated patients was performed in order to investigate the benefits of $\mathrm{N}$-acetylcysteine treatment in addition to the standard treatment that included benzylpenicillin in patients with A. phalloides intoxication (Akin et al., 2013). The mortality rate was lower when N-acetylcysteine was coadministered ( $4.4 \%$ vs $18.7 \%$ in the group that received only benzylpenicillin). Thus, the authors concluded that $A$. phalloides intoxication could be successfully treated with $\mathrm{N}$-acetylcysteine in addition with benzylpenicillin (Akin et al., 2013). N-acetylcysteine can act at two levels: by direct ROS scavenging and/or restoring hepatic GSH (Poucheret et al., 2010). In accordance, a recent in vitro study showed that treatment of human hepatocyte cultures with $\mathrm{N}$-acetylcysteine gave a strong protective effect against subsequent $\alpha$-amanitin cytotoxicity (Magdalan et al., 2010a).

On the other hand, research previously conducted by Schneider et al. and Tong et al. failed to show any relevant clinical efficacy of $\mathrm{N}$-acetylcysteine in the treatment of $A$. phalloides intoxication in mice (Schneider et al., 1992; Tong et al., 2007). Both studies used $1.2 \mathrm{~g} / \mathrm{kg}$ of $\mathrm{N}$-acetylcysteine administered $4 \mathrm{~h}$ after intraperitoneal administration of $\alpha$-amanitin $(0.6 \mathrm{mg} / \mathrm{kg}$ ). Efficacy data of $\mathrm{N}$-acetylcysteine administration in $\alpha$-amanitin-intoxicated dogs are lacking. However, it is reasonable to consider that there is no reason to not include $\mathrm{N}$-acetylcysteine in the treatment regimen.

CIAV and TOXBASE protocols for $A$. phalloides poisoning do not include administration of N-acetylcysteine (CIAV, 2014; TOXBASE, 2008), whereas the national poisons center of New Zealand recommends to administer $150 \mathrm{mg} / \mathrm{kg}$ in $200 \mathrm{~mL}$ vehicle (5\% dextrose in water) intravenously over $15 \mathrm{~min}$ followed by $50 \mathrm{mg} / \mathrm{kg}$ in $500 \mathrm{~mL}$ vehicle over $4 \mathrm{~h}$ followed by $100 \mathrm{mg} / \mathrm{kg}$ in $1000 \mathrm{~mL}$ vehicle over 16 h (Toxinz, 2013).

2.6.5.3. Liver transplantation. In some cases of $A$. phalloides poisoning, acute liver failure can be developed and a consequent liver transplant is needed to guarantee patients' survival. Acute liver failure has a devastating effect characterized by sudden and severe liver cell dysfunction. This catastrophic illness can rapidly progress to coma and death due to cerebral edema and multi-organ system failure (Larson, 2008). Several criteria to decide the timing of liver transplantation have been proposed, although they are not universally accepted. The most widely used criteria for liver transplantation were developed by The Liver Unit at King's College Hospital (O'Grady et al., 1989). Their prognostic model was based on prothrombin time, age, etiology, time passing between appearance of jaundice and onset of encephalopathy, and bilirubin concentration. These criteria differentiate acetaminophen and non-acetaminophen induced acute liver failure. The King's College Hospital prognostic criteria for non-paracetamol-induced fulminant hepatic failure includes: prothrombin time $>100 \mathrm{~s}$; and any three of the following: age $<10$ or $>40$ years; jaundice $>7$ days before onset of encephalopathy, prothrombin time $>50 \mathrm{~s}$ and bilirubin $>300 \mu \mathrm{mol} / \mathrm{l}$ (O'Grady et al., 1989). However, the application of King's college criteria for non-acetaminophen induced acute hepatic failure on $A$. phalloides poisoning is limited (O'Grady et al., 1989). Not all variables included in these criteria are useful in predicting a fatal outcome. In a distinct rationale, liver transplantation based on the Clichy criteria include the combination of decrease in factor $\mathrm{V}$ below $30 \%$ of normal patients over 30 years or below $20 \%$ of normal patients below 30 years and grade 3-4 encephalopathy (Bernuau, 1993). On the other hand, a retrospective study of 198 amatoxins intoxicated patients showed that prothrombin index $<25 \%$ in combination with serum creatinine $>106 \mu \mathrm{mol} / \mathrm{L}$ from day 3-10 after $A$. phalloides ingestion is a strong predictor of fatal outcome (Ganzert et al., 2005). Ganzert's criteria do not include the evaluation of hepatic encephalopathy due to imprecise data in the patients' records (Ganzert et al., 2005). In order to reassess the transplantation criteria, Escudie et al. studied $27 \mathrm{~A}$. phalloides poisoned patients and the above criteria were compared. Encephalopathy, an absolute prerequisite in Clichy criteria for deciding emergency transplantation, was not fully observed in this study (Escudie et al., 2007). Not all patients with a fatal outcome developed encephalopathy and, in those who developed, the mean interval between the onset of encephalopathy and death was very short (Escudie et al., 2007). Comparing to the Ganzert's criteria, the prothrombin index below or equal to $25 \%$ of normal values, between day 3 and day 10 after amatoxins ingestion, was refuted by Escudie et al. (2007). Their findings showed that $52 \%$ of patients that had a decrease in prothrombin index recovered without the need of transplantation. The authors concluded that such prothrombin index should be lowered in order to avoid unnecessary transplantation (Escudie et al., 2007). Moreover, it was also shown that the value of serum creatinine has some limitations. Escudie et al. (2007) found that not all patients with fatal outcome had a creatinine level over $106 \mu \mathrm{mol} / \mathrm{L} 3$ days or more after ingestion. The authors suggested that serum creatinine should not be an absolute requirement for emergency transplantation. They also pointed out that liver transplantation should be strongly recommended in patients with an interval between ingestion of 
mushrooms and the onset diarrhea lower than $8 \mathrm{~h}$ (Escudie et al., 2007). In addition to this interval, females were also more at risk for a fatal outcome than males. Lastly, decrease in prothrombin index below $10 \%$ of normal (international normalized ratio > 6) 4 days or more after ingestion should be a strong plus to consider an emergency transplantation (Escudie et al., 2007).

A recent publication has shown that polymyxin B has partially prevented the amanitin-induced toxicity when a lethal dose of $\alpha$ amanitin was used in CD-1 mice. As polymyxin B showed in silico and in vivo to avoid RNA polymerase II inactivation (Garcia et al., 2015d), this recent finding further support the new paradigm of antidotal route for Amanita phalloides poisoning focusing on RNA polymerase II.

\section{Conclusions}

A. phalloides is one of the most toxic mushrooms and is involved in the majority of human fatal cases of mushroom poisoning. The true incidence of amatoxin poisoning is unknown due to sub notification cases of intoxication cases, and therefore mortality rates reported in the literature may be significantly underestimated.

When A. phalloides poisoning occurs, most patients are admitted to hospital at a late stage, and often no appropriate tools for analyzing amatoxins or corroborate the poisoning are available. The presumed diagnosis of amatoxin poisoning is often suggested based on a gastrointestinal syndrome preceded by a latent period and a history of mushrooms ingestion. Treatment often aims decontamination, control of fluid and electrolyte balance and prevention of multiple organ failure, especially liver failure.

The optimal management of the A. phalloides poisoning remains to be determined, which makes difficult the establishment of a worldwide standard treatment. In fact, this can explain the therapeutic differences between the different poisons centers analyzed throughout the globe. Some options have been employed and include detoxification measures, chemotherapy, and liver transplantation as the last resort. Retrospective analysis of the applied therapy, specifically using benzylpenicillin, ceftazidime, silybin, and $\mathrm{N}-$ acetylcysteine, has revealed contradictory results regarding to their clinical effectiveness. The lack of randomized, controlled clinical trials in combination with the use of combined therapy and the overall underreported intoxication cases limit the true evaluation of the efficacy of a specific therapy. Silybin seems a promising drug to prevent amatoxins-induced intoxications symptomatology demonstrating a good safety profile and so far it has presented the lowest mortality rate of the applied treatments. Despite the mortality rate being below $10 \%$, the patients' prognosis largely depends on the prompt recognition and treatment. Even so, more clinical studies and in vivo experimental data are needed to prove its use in the clinical practice.

Emergency liver transplantation is the only intervention with recognized survival benefits in acute liver failure patients with a poor prognosis. Nevertheless, liver failure may develop rapidly within days, hindering timely hepatic transplant.

Inhibition of the RNAP II has been postulated to be the main toxic mechanism of $\alpha$-amanitin. Other mechanisms have been pointed but need further investigation. A more detailed understanding of the above mechanism will aid in the development of effective and more powerful drugs for treating amatoxins poisoning. An important approach would be to develop an antidote that competes with amatoxins and displaces them from RNAP II. In fact, an optimal agent should be able to bind to RNAP II protecting against amatoxins while not disturbing the normal transcription process.

\section{Acknowledgments}

This work was supported by the Fundação para a Ciência e Tecnologia (FCT) - project PTDC/DTPFTO/4973/2014 - and the European Union (FEDER funds through COMPETE) and National Funds (FCT, Fundação para a Ciência e Tecnologia) through project PestC/EQB/LA0006/2013. Juliana Garcia and Vera Marisa Costa thank FCT for their PhD grant (SFRH/BD/74979/2010) and Post-doc grants (SFRH/BPD/63746/2009 and SFRH/BPD/110001/2015), respectively.

\section{Transparency document}

Transparency document related to this article can be found online at http://dx.doi.org/10.1016/j.fct.2015.09.008.

\section{References}

Ahishali, E., Boynuegri, B., Ozpolat, E., Surmeli, H., Dolapcioglu, C., Dabak, R., Bahcebasi, Z.B., Bayramicli, O.U., 2012. Approach to mushroom intoxication and treatment: can we decrease mortality? Clin. Res. Hepatol. Gastroenterol. 36, 139-145.

Ahmed, W., Gonmori, K., Suzuki, M., Watanabe, K., Suzuki, O., 2010. Simultaneous analysis of $\alpha$-amanitin, $\beta$-amanitin, and phalloidin in toxic mushrooms by liquid chromatography coupled to time-of-flight mass spectrometry. Forensic Toxicol. 28, 69-76.

Akin, A., Ozgur, S., Kiliç, D., Aliustaoglu, M., Keskek, N., 2013. The effects of Nacetylcysteine in patients with amanita phalloides intoxication. J. Drug Toxicol. 4,3

Albertson, T.E., Owen, K.P., Sutter, M.E., Chan, A.L., 2011. Gastrointestinal decontamination in the acutely poisoned patient. Int. J. Emerg. Med. 4, 65.

Alves, A., Gouveia Ferreira, M., Paulo, J., Franca, A., Carvalho, A., 2001. Mushroom poisoning with Amanita phalloides - a report of four cases. Eur. J. Intern Med. $12,64-66$.

Amini, M., Ahmadabadi, A., Kazemifar, A.M., Solhi, H., Jand, Y, 2011. Amanita phalloides intoxication misdiagnosed as acute appendicitis: a case report. Iran. J. Toxicol. 5, 527-530.

Arima, Y., Nitta, M., Kuninaka, S., Zhang, D., Fujiwara, T., Taya, Y., Nakao, M., Saya, H., 2005. Transcriptional blockade induces p53-dependent apoptosis associated with translocation of p53 to mitochondria. J. Biol. Chem. 280, 1916619176.

Barceloux, D.G., 2008. Medical Toxicology of Natural Substances: Foods, Fungi, Medicinal Herbs, Plants, and Venomous Animals. Wiley.

Becker, C.E., Tong, T.G., Boerner, U., Roe, R.L., Sco, T.A., MacQuarrie, M.B., Bartter, F., 1976. Diagnosis and treatment of Amanita phalloides-type mushroom poisoning: use of thioctic acid. West J. Med. 125, 100-109.

Bergis, D., Friedrich-Rust, M., Zeuzem, S., Betz, C., Sarrazin, C., Bojunga, J., 2012. Treatment of Amanita phalloides intoxication by fractionated plasma separation and adsorption (Prometheus(R)). J. Gastrointestin Liver Dis. 21, 171-176.

Bernuau, J., 1993. Selection for emergency liver transplantation. J. Hepatol. 19, 486487.

Beuhler, M., Lee, D.C., Gerkin, R., 2004. The meixner test in the detection of alpha-amanitin and false-positive reactions caused by psilocin and 5-substituted tryptamines. Ann. Emerg. Med. 44, 114-120.

Bleuter, J.A., Vergeer, A.A., 1980. Amatoxins in American mushrooms: evaluation of the meixner test. Mycologia 72, 1142-1149.

Block, S.S., Stephens, R.L., Murrill, W.A., 1955. Natural food poisons, amanita toxins in mushrooms. J. Agr Food Chem. 3, 584-587.

Bonnet, M.S., Basson, P.W., 2002. The toxicology of Amanita phalloides. Homeopathy 91, 249-254.

Brandão, J.L., Pinheiro, J., Pinho, D., Correia da Silva, D., Fernandes, E., Fragoso, G., Costa, M.I., Silva, A., 2011. Intoxicação por cogumelos em portugal. Acta Med. Port. 24, 269-278

Brossi, A., 1991. The Alkaloids: Chemistry and Pharmacology V40: Chemistry and Pharmacology. Elsevier Science.

Broussard, C.N., Aggarwal, A., Lacey, S.R., Post, A.B., Gramlich, T., Henderson, J.M., Younossi, Z.M., 2001. Mushroom poisoning-from diarrhea to liver transplantation. Am. J. Gastroenterol. 96, 3195-3198.

Bushnell, D.A., Cramer, P., Kornberg, R.D., 2002. Structural basis of transcription: alpha-amanitin-RNA polymerase II cocrystal at 2.8 A resolution. Proc. Natl. Acad. Sci. U. S. A. 99, 1218-1222.

Butera, R., Locatelli, C., Coccini, T., Manzo, L., 2004. Diagnostic accuracy of urinary amanitin in suspected mushroom poisoning: a pilot study. J. Toxicol. Clin. Toxicol. 42, 901-912.

Cheung, P.C.K., 2010. The nutritional and health benefits of mushrooms. Nutr. Bull. 35, 292-299.

Chung, W.C. Tso, S.C. Sze, S.T. 2007. Separation of polar mushroom toxins by mixed-mode hydrophilic and ionic interaction liquid chromatographyelectrospray ionization-mass spectrometry. J. Chromatogr. Sci. 45, 104-111. 
CIAV, 2014. Centro de informação antivenenos: Protocolo terapêutico preconizado pelo CIAV nos casos de intoxicação por Amanita Phalloides.

Cochet-Meilhac, M., Chambon, P., 1974. Animal DNA-dependent RNA polymerases. 11. Mechanism of the inhibition of RNA polymerases B by amatoxins. Biochim. Biophys. Acta 353, 160-184.

Cooper, J.A., 1987. Effects of cytochalasin and phalloidin on actin. J. Cell Biol. 105, 1473-1478.

Dancker, P., Low, I., Hasselbach, W., Wieland, T., 1975. Interaction of actin with phalloidin: polymerization and stabilization of F-actin. Biochim. Biophys. Acta 400, 407-414.

Derelanko, M.J., Hollinger, M.A., 2001. Handbook of Toxicology, second ed. Taylor \& Francis.

Deshpande, S.S., 2002. Handbook of Food Toxicology. Taylor \& Francis.

Diaz, J.H., 2005a. Evolving global epidemiology, syndromic classification, general management, and prevention of unknown mushroom poisonings. Crit. Care Med. 33, 419-426.

Diaz, J.H., 2005b. Syndromic diagnosis and management of confirmed mushroom poisonings. Crit. Care Med. 33, 427-436.

El-Bahay, C., Gerber, E., Horbach, M., Tran-Thi, Q.H., Rohrdanz, E., Kahl, R., 1999. Influence of tumor necrosis factor-alpha and silibin on the cytotoxic action of alpha-amanitin in rat hepatocyte culture. Toxicol. Appl. Pharmacol. 158, 253260 .

Enjalbert, F., Cassanas, G., Guinchard, C., Chaumont, J.P., 1996. Toxin composition of Amanita phalloides tissues in relation to the collection site. Mycologia 88, 909921.

Enjalbert, F., Cassanas, G., Rapior, S., Renault, C., Chaumont, J.P., 2004. Amatoxins in wood-rotting Galerina marginata. Mycologia 96, 720-729.

Enjalbert, F., Cassanas, G., Salhi, S.L., Guinchard, C., Chaumont, J.P., 1999. Distribution of the amatoxins and phallotoxins in Amanita phalloides. Influence of the tissues and the collection site. C R. Acad. Sci. III 322, 855-862.

Enjalbert, F., Gallion, C., Jehl, F., Monteil, H., 1993. Toxin content, phallotoxin and amatoxin composition of Amanita phalloides tissues. Toxicon 31, 803-807.

Enjalbert, F., Gallion, C., Jehl, F., Monteil, H., Faulstich, H., 1992. Simultaneous assay for amatoxins and phallotoxins in Amanita phalloides Fr. by high-performance liquid chromatography. J. Chromatogr. 598, 227-236.

Enjalbert, F., Rapior, S., Nouguier-Soule, J., Guillon, S., Amouroux, N., Cabot, C., 2002. Treatment of amatoxin poisoning: 20-year retrospective analysis. J. Toxicol. Clin. Toxicol. 40, 715-757.

Eren, S.H., Demirel, Y., Ugurlu, S., Korkmaz, I., Aktas, C., Güven, F.M.K., 2010. Mushroom poisoning: retrospective analysis of 294 cases. Clinics 65, 491-496.

Escudie, L., Francoz, C., Vinel, J.P., Moucari, R., Cournot, M., Paradis, V., Sauvanet, A., Belghiti, J., Valla, D., Bernuau, J., Durand, F., 2007. Amanita phalloides poisoning: reassessment of prognostic factors and indications for emergency liver transplantation. J. Hepatol. 46, 466-473.

Fantozzi, R., Ledda, F., Caramelli, L., Moroni, F., Blandina, P., Masini, E., Botti, P. Peruzzi, S., Zorn, M., Mannaioni, P.F., 1986. Clinical findings and follow-up evaluation of an outbreak of mushroom poisoning-survey of Amanita phalloides poisoning. Klin. Wochenschr. 64, 38-43.

Faulstich, H., 1979. New aspects of amanita poisoning. Klin. Wochenschr 57, 11431152.

Faulstich, H., Buku, A., Bodenmuller, H., Wieland, T., 1980. Virotoxins: actin-binding cyclic peptides of Amanita virosa mushrooms. Biochemistry 19, 3334-3343.

Faulstich, H., Talas, A., Wellhoner, H.H., 1985. Toxicokinetics of labeled amatoxins in the dog. Arch. Toxicol. 56, 190-194.

Feinfeld, D.A., Mofenson, H.C., Caraccio, T., Kee, M., 1994. Poisoning by amatoxincontaining mushrooms in suburban New York-report of four cases. J. Toxicol. Clin. Toxicol. 32, 715-721.

Fineschi, V., Di Paolo, M., Centini, F., 1996. Histological criteria for diagnosis of amanita phalloides poisoning. J. Forensic Sci. 41, 429-432.

Floersheim, G.L., 1983. Toxins and intoxications from the toadstool Amanita phalloides. Trends Pharmacol. Sci. 4, 263-266.

Floersheim, G.L., Eberhard, M., Tschumi, P., Duckert, F., 1978. Effects of penicillin and silymarin on liver enzymes and blood clotting factors in dogs given a boiled preparation of Amanita phalloides. Toxicol. Appl. Pharmacol. 46, 455462 .

Floersheim, G.L., Weber, O., Tschumi, P., Ulbrich, M., 1982. Clinical death-cap (Amanita phalloides) poisoning: prognostic factors and therapeutic measures. Analysis of 205 cases. Schweiz Med. Wochenschr 112, 1164-1177.

Fraschini, F., Demartini, G., Esposti, D., 2002. Pharmacology of silymarin. Clin. Drug Invest. 22, 51-65.

Gabbiani, G., Montesano, R., Tuchweber, B., Salas, M., Orci, L., 1975. Phalloidininduced hyperplasia of actin filaments in rat hepatocytes. Lab. Invest. 33, 562569.

Ganzert, M., Felgenhauer, N., Zilker, T., 2005. Indication of liver transplantation following amatoxin intoxication. J. Hepatol. 42, 202-209.

Garcia, J., Carvalho, A.T.P., Dourado, D.F.A.R., Baptista, P., de Lourdes Bastos, M., Carvalho, F., 2014. New in silico insights into the inhibition of RNAP II by $\alpha$-amanitin and the protective effect mediated by effective antidotes. J. Mol. Graph. Modell. 51, 120-127.

Garcia, J., Costa, V.M., Baptista, P., de Lourdes Bastos, M., Carvalho, F., 2015a. Quantification of alpha-amanitin in biological samples by HPLC using simultaneous UV- diode array and electrochemical detection. J. Chromatogr. B 997, 85-95.

Garcia, J., Costa, V.M., Costa, A.E., Andrade, S., Carneiro, A.C., Conceição, F., Paiva, J.A. de Pinho, P.G., Baptista, P., de Lourdes Bastos, M., Carvalho, F., 2015b. Coingestion of amatoxins and isoxazoles-containing mushrooms and successful treatment: a case report. Toxicon 103, 55-59.
Garcia, J.V., Oliveira, A., Pinho, P.G., Freitas, V., Carvalho, A., Baptista, P., Carvalho, E. de Lourdes Bastos, M., Carvalho, F., 2015c. Determination of Amatoxins and phallotoxins in Amanita phalloides mushrooms from northeastern Portugal by HPLC-DAD-MS. Mycologia 107, 679-687.

Garcia, J., Costa, V.M., Carvalho, A.T.P., Silvestre, R., Duarte, J.A., Dourado, D.F.A.R., Arbo, M., Baltazar, T., Dinis-Oliveira, R.J., Baptista, P., Bastos, M.L., Carvalho, F., 2015d. A breakthrough on Amanita phalloides poisoning: an effective antidotal effect by polymyxin B. Arch. Toxicol. http://dx.doi.org/10.1007/ s00204-015-1582-X.

Giannini, L., Vannacci, A., Missanelli, A., Mastroianni, R., Mannaioni, P.F., Moroni, F, Masini, E., 2007. Amatoxin poisoning: a 15-year retrospective analysis and follow-up evaluation of 105 patients. Clin. Toxicol. 45, 539-542.

Himmelmann, A., Mang, G., Schnorf-Huber, S., 2001. Lethal ingestion of stored Amanita phalloides mushrooms. Swiss Med. Wkly. 131, 616-617.

Homann, J., Rawer, P., Bleyl, H., Matthes, K.J., Heinrich, D., 1986. Early detection of amatoxins in human mushroom poisoning. Arch. Toxicol. 59, 190-191.

Hruby, K., Csomos, G., Fuhrmann, M., Thaler, H., 1983. Chemotherapy of Amanita phalloides poisoning with intravenous silibinin. Hum. Toxicol. 2, 183-195.

Hu, J., Zhang, P., Zeng, J., Chen, Z., 2012. Determination of amatoxins in different tissues and development stages of Amanita exitialis. J. Sci. Food Agric. 92, 26642667.

Jaeger, A., Jehl, F., Flesch, F., Sauder, P., Kopferschmitt, J., 1993. Kinetics of amatoxins in human poisoning: therapeutic implications. J. Toxicol. Clin. Toxicol. 31, 63-80.

James, L.P., Mayeux, P.R., Hinson, J.A., 2003. Acetaminophen-induced hepatotoxicity. Drug Metab. Dispos. 31, 1499-1506.

Jander, S., Bischoff, J., Woodcock, B.G., 2000. Plasmapheresis in the treatment of Amanita phalloides poisoning: II. A review and recommendations. Ther. Apher. 4, 308-312.

Jansson, D., Fredriksson, S.A., Herrmann, A., Nilsson, C., 2012. A concept study on identification and attribution profiling of chemical threat agents using liquid chromatography-mass spectrometry applied to Amanita toxins in food. Forensic Sci. Int. 221, 44-49.

Kaneko, H., Tomomasa, T., Inoue, Y., Kunimoto, F., Fukusato, T., Muraoka, S., Gonmori, K., Matsumoto, T., Morikawa, A., 2001. Amatoxin poisoning from ingestion of Japanese Galerina mushrooms. J. Toxicol. Clin. Toxicol. 39, 413416.

Kaplan, C.D., Larsson, K.M., Kornberg, R.D., 2008. The RNA polymerase II trigger loop functions in substrate selection and is directly targeted by alpha-amanitin. Mol. Cell. 30, 547-556.

Karlson-Stiber, C., Persson, H., 2003. Cytotoxic fungi-an overview. Toxicon 42, 339349.

Kaya, E., Surmen, M.G., Yaykasli, K.O., Karahan, S., Oktay, M., Turan, H., Colakoglu, S., Erdem, H., 2014. Dermal absorption and toxicity of alpha amanitin in mice. Cutan. Ocul. Toxicol. 33, 154-160.

Koda-Kimble, M.A., Alldredge, B.K., Corelli, R.L., Ernst, M.E., 2012. Koda-kimble and Young's Applied Therapeutics: the Clinical Use of Drugs. Wolters Kluwer Health.

Koppel, C., 1993. Clinical symptomatology and management of mushroom poisoning. Toxicon 31, 1513-1540.

Krenova, M., Pelclova, D., Navratil, T., 2007. Survey of Amanita phalloides poisoning: clinical findings and follow-up evaluation. Hum. Exp. Toxicol. 26, 955-961.

Kroncke, K.D., Fricker, G., Meier, P.J., Gerok, W., Wieland, T., Kurz, G., 1986. alphaAmanitin uptake into hepatocytes. Identification of hepatic membrane transport systems used by amatoxins. J. Biol. Chem. 261, 12562-12567.

Kucuk, H.F., Karasu, Z., Kılıc, M., Nart, D., 2005. Liver failure in transplanted liver due to amanita falloides. Transplant. Proc. 37, 2224-2226.

Larson, A.M., 2008. Acute liver failure. Dis. Mon. 54, 457-485.

Leist, M., Gantner, F., Naumann, H., Bluethmann, H., Vogt, K., Brigelius-Flohe, R. Nicotera, P., Volk, H.D., Wendel, A., 1997. Tumor necrosis factor-induced apoptosis during the poisoning of mice with hepatotoxins. Gastroenterology 112, 923934.

Letschert, K., Faulstich, H., Keller, D., Keppler, D., 2006. Molecular characterization and inhibition of amanitin uptake into human hepatocytes. Toxicol. Sci. 91, 140149.

Leu, J.I., George, D.L., 2007. Hepatic IGFBP1 is a prosurvival factor that binds to BAK, protects the liver from apoptosis, and antagonizes the proapoptotic actions of p53 at mitochondria. Genes Dev. 21, 3095-3109.

Lionte, C., Sorodoc, L., Simionescu, V., 2005. Successful treatment of an adult with Amanita phalloides-induced fulminant liver failure with molecular adsorbent recirculating system (MARS). Rom. J. Gastroenterol. 14, 267-271.

Ljungman, M., Zhang, F., Chen, F., Rainbow, A.J., McKay, B.C., 1999. Inhibition of RNA polymerase II as a trigger for the p53 response. Oncogene 18, 583-592.

Loranger, A., Tuchweber, B., Gicquaud, C., St-Pierre, S., Cote, M.G., 1985. Toxicity of peptides of Amanita virosa mushrooms in mice. Fundam. Appl. Toxicol. 5, 11441152.

Luper, S., 1998. A review of plants used in the treatment of liver disease: part 1. Altern. Med. Rev. 3, 410-421.

Lynen, F., Wieland, U., 1938. Über die Giftstoffe des Knollenblätterpilzes. IV. Justus Liebigs Ann. Chem. 533, 93-117.

Magdalan, J., Ostrowska, A., Piotrowska, A., Gomulkiewicz, A., PodhorskaOkolow, M., Patrzalek, D., Szelag, A., Dziegiel, P., 2010a. Benzylpenicillin, acetylcysteine and silibinin as antidotes in human hepatocytes intoxicated with alpha-amanitin. Exp. Toxicol. Pathol. 62, 367-373.

Magdalan, J., Ostrowska, A., Piotrowska, A., Gomulkiewicz, A., Szelag, A. Dziedgiel, P., 2009. Comparative antidotal efficacy of benzylpenicillin, ceftazidime and rifamycin in cultured human hepatocytes intoxicated with alphaamanitin. Arch. Toxicol. 83, 1091-1096. 
Magdalan, J., Ostrowska, A., Piotrowska, A., Izykowska, I., Nowak, M., Gomulkiewicz, A., Podhorska-Okolow, M., Szelag, A., Dziegiel, P., 2010b. alpha-Amanitin induced apoptosis in primary cultured dog hepatocytes. Folia Histochem Cytobiol. 48, 58-62.

Magdalan, J., Piotrowska, A., Gomulkiewicz, A., Sozanski, T., Podhorska-Okolow, M. Szelag, A., Dziegiel, P., 2011. Benzylpenicyllin and acetylcysteine protection from alpha-amanitin-induced apoptosis in human hepatocyte cultures. Exp. Toxicol. Pathol. 63, 311-315.

Mas, A., 2005. Mushrooms, amatoxins and the liver. J. Hepatol. 42, 166-169.

Mengs, U., Pohl, R.T., Mitchell, T., 2012. Legalon(R) SIL: the antidote of choice in patients with acute hepatotoxicity from amatoxin poisoning. Curr. Pharm. Biotechnol. 13, 1964-1970.

Moroni, F., Fantozzi, R., Masini, E., Mannaioni, P.F., 1976. A trend in the therapy of Amanita phalloides poisoning. Arch. Toxicol. 36, 111-115.

Mowry, J.B., Spyker, D.A., Cantilena Jr., L.R., Bailey, J.E., Ford, M., 2013. 2012 Annual report of the American Association of Poison Control Centers' National Poison Data System (NPDS): 30th annual report. Clin. Toxicol. Phila 51, 9491229.

Mydlik, M., Derzsiova, K., 2006. Liver and kidney damage in acute poisonings. Bantao J. 4, 30-32.

Nguyen, V.T., Giannoni, F., Dubois, M.-F., Seo, S.-J., Vigneron, M., Kédinger, C., Bensaude, O., 1996. Vivo degradation of RNA polymerase II largest subunit triggered by $\alpha$-amanitin. Nucleic Acids Res. 24, 2924-2929.

O'Grady, J.G., Alexander, G.J., Hayllar, K.M., Williams, R., 1989. Early indicators of prognosis in fulminant hepatic failure. Gastroenterology 97, 439-445.

Olson, K.R., Pond, S.M., Seward, J., Healey, K., Woo, O.F., Becker, C.E., 1982. Amanita phalloides-type mushroom poisoning. West J. Med. 137, 282-289.

Pilz, D., Molina, R., 2002. Commercial harvests of edible mushrooms from the forests of the Pacific Northwest United States: issues, management, and monitoring for sustainability. For. Ecol. Manag. 155, 3-16.

Pinson, C.W. Daya, M.R. Benner, K.G., Norton, R.L., Deveney, K.E., Kurkchubasche, A.G., Ragsdale, J.W., Alexander, J.P., Keeffe, E.B., Ascher, N.L. Roberts, J.P., Lake, J.R., 1990. Liver transplantation for severe Amanita phalloides mushroom poisoning. Am. J. Surg. 159, 493-499.

Pond, S.M., Olson, K.R., Woo, O.F., Osterloh, J.D., Ward, R.E., Kaufman, D.A. Moody, R.R., 1986. Amatoxin poisoning in northern California, 1982-1983. West J. Med. 145, 204-209.

Poucheret, P., Fons, F., Dore, J.C., Michelot, D., Rapior, S., 2010. Amatoxin poisoning treatment decision-making: pharmaco-therapeutic clinical strategy assessment using multidimensional multivariate statistic analysis. Toxicon 55, 13381345.

Pradhan, S.C., Girish, C., 2006. Hepatoprotective herbal drug, silymarin from experimental pharmacology to clinical medicine. Indian J. Med. Res. 124, 491504.

Reid, D.A., Eicker, A., 1991. South African fungi: the genus Amanita. Mycol. Res. 95, 80-95.

Rittgen, J., Putz, M., Pyell, U., 2008. Identification of toxic oligopeptides in Amanita fungi employing capillary electrophoresis-electrospray ionization-mass spectrometry with positive and negative ion detection. Electrophoresis 29, 20942100.

Roberts, D.M., Hall, M.J., Falkland, M.M., Strasser, S.I., Buckley, N.A., 2013. Amanita phalloides poisoning and treatment with silibinin in the Australian Capital Territory and New South Wales. Med. J. Aust. 198, 43-47.

Rudd, M.D., Luse, D.S., 1996. Amanitin greatly reduces the rate of transcription by RNA polymerase II ternary complexes but fails to inhibit some transcript cleavage modes. J. Biol. Chem. 271, 21549-21558.

Santi, L., Maggioli, C., Mastroroberto, M., Tufoni, M., Napoli, L., Caraceni, P., 2012. Acute liver failure caused by amanita phalloides poisoning. Int. J. Hepatol. 2012 6.

Sanz, P., Reig, R., Borras, L., Martinez, J., Manez, R., Corbella, J., 1988. Disseminated intravascular coagulation and mesenteric venous thrombosis in fatal Amanita poisoning. Hum. Toxicol. 7, 199-201.

Schenk-Jaeger, K.M., Rauber-Luthy, C., Bodmer, M., Kupferschmidt, H., KullakUblick, G.A., Ceschi, A., 2012. Mushroom poisoning: a study on circumstances of exposure and patterns of toxicity. Eur. J. Intern Med. 23, e85-91.
Schneider, S.M., Michelson, E.A., Vanscoy, G., 1992. Failure of N-acetylcysteine to reduce alpha amanitin toxicity. J. Appl. Toxicol. 12, 141-142.

Serne, E.H., Toorians, A.W., Gietema, J.A., Bronsveld, W., Haagsma, E.B., Mulder, P.O. 1996. Amanita phalloides, a potentially lethal mushroom: its clinical presentation and therapeutic options. Neth J. Med. 49, 19-23.

Seymour, F.K., Henry, J.A., 2001. Assessment and management of acute poisoning by petroleum products. Hum. Exp. Toxicol. 20, 551-562.

Shi, Y., He, J., Chen, S., Zhang, L., Yang, X., Wang, Z., Wang, M., 2002. MARS: optimistic therapy method in fulminant hepatic failure secondary to cytotoxic mushroom poisoning-a case report. Liver 22 (Suppl. 2), 78-80.

Soysal, D., Cevik, C., Saklamaz, A., Yetimalar, Y., Unsal, B., 2006. Coagulation disorders secondary to acute liver failure in Amanita phalloides poisoning: a case report. Turk J. Gastroenterol. 17, 198-202.

Tong, T.C., Hernandez, M., Richardson 3rd, W.H., Betten, D.P., Favata, M. Riffenburgh, R.H., Clark, R.F., Tanen, D.A., 2007. Comparative treatment of alphaamanitin poisoning with $\mathrm{N}$-acetylcysteine, benzylpenicillin, cimetidine, thioctic acid, and silybin in a murine model. Ann. Emerg. Med. 50, 282-288.

TOXBASE, 2008. TOXBASE Clinical Toxicology Database of the United Kingdom National Poisons Information Service: Amanita Phalloides-features and Management www.toxibase.org.

Toxinz, 2013. Amanita Phalloides. National Poisons Centre, New Zealand www. toxinz.com.

Trim, G.M., Lepp, H., Hall, M.J., McKeown, R.V., McCaughan, G.W., Duggin, G.G., Le Couteur, D.G., 1999. Poisoning by Amanita phalloides ("deathcap") mushrooms in the Australian Capital Territory. Med. J. Aust. 171, 247-249.

Turcotte, A., Gicquaud, C., Gendreau, M., St-Pierre, S., 1984. Séparation des virotoxines du champignon Amanita virosa et étude comparative de leur interaction sur l'actine in vitro. Can. J. Biochem. Cell B 62, 1327-1334.

Vale, J.A., 1997. Position statement: gastric lavage. American Academy of clinical toxicology; european association of poisons centres and clinical toxicologists. J. Toxicol. Clin. Toxicol. 35, 711-719.

Vale, J.A., Kulig, K., American Academy of Clinical, T., European Association of Poisons, C., Clinical, T., 2004. Position paper: gastric lavage. J. Toxicol. Clin. Toxicol. 42, 933-943.

Vetter, J., 1998. Toxins of Amanita phalloides. Toxicon 36, 13-24.

Vogel, G., Tuchweber, B., Trost, W., Mengs, U., 1984. Protection by silibinin against Amanita phalloides intoxication in beagles. Toxicol. Appl. Pharmacol. 73, 355362.

Wang, D., Bushnell, D.A., Westover, K.D., Kaplan, C.D., Kornberg, R.D., 2006. Structural basis of transcription: role of the trigger loop in substrate specificity and catalysis. Cell 127, 941-954.

Ward, J., Kapadia, K., Brush, E., Salhanick, S.D., 2013. Amatoxin poisoning: case reports and review of current therapies. J. Emerg. Med. 44, 116-121.

Wieland, T., 1976. Interaction of phallotoxins with actin. Adv. Enzyme Regul. 15, 285-300.

Wieland, T., 1983. The toxic peptides from Amanita mushrooms. Int. J. Pept. Protein Res. 22, 257-276.

Wieland, T., Faulstich, H., 1978. Amatoxins, phallotoxins, phallolysin, and antamanide: the biologically active components of poisonous Amanita mushrooms. CRC Crit. Rev. Biochem. 5, 185-260.

Wong, J.H., 2013. Chapter 25-Fungal toxins. In: Kastin, A.J. (Ed.), Handbook of Biologically Active Peptides. Academic Press, Boston, pp. 166-168.

Wlcek, K., Koller, F., Ferenci, P., Stieger, B., 2013. Hepatocellular organic aniontransporting polypeptides (OATPs) and multidrug resistance-associated protein 2 (MRP2) are inhibited by silibinin. Drug Metab. Dispos. 41 (8), 1522-1528.

Ytrebo, L.M., Sen, S., Rose, C., Ten Have, G.A., Davies, N.A., Hodges, S., Nedredal, G.I. Romero-Gomez, M., Williams, R., Revhaug, A., Jalan, R., Deutz, N.E., 2006. Interorgan ammonia, glutamate, and glutamine trafficking in pigs with acute liver failure. Am. J. Physiol. Gastrointest. Liver Physiol. 291, G373-G381.

Zheleva, A., 2013. Phenoxyl radicals formation might contribute to severe toxicity of mushrooms toxin alpha-amanitin- an electron paramagnetic resonance study. TJS 11, 33-38.

Zheleva, A., Tolekova, A., Zhelev, M., Uzunova, V., Platikanova, M., Gadzheva, V., 2007. Free radical reactions might contribute to severe alpha amanitin hepatotoxicity-a hypothesis. Med. Hypotheses 69, 361-367. 